\title{
NUEVOS REGISTROS DE MADERAS DEL MIOCENO DE LA FORMACIÓN SOLIMÕES, CUENCA DE ACRE, AMAZONIA, BRASIL
}

\author{
ADRIANA KLOSTER \\ Consejo Nacional de Investigaciones Científicas y Técnicas (CECOAL-CONICET). Ruta 5 km 2,5 3400, \\ Corrientes, Argentina. klosterdri@gmail.com
}

SILVIA GNAEDINGER

Área de Paleontología, Centro de Ecología Aplicada del Litoral, Consejo Nacional de Investigaciones Científicas y Técnicas (CECOAL-CCT CONICET Nordeste-UNNE), Facultad de Ciencias Exactas y Naturales y Agrimensura, Universidad Nacional del Nordeste (FaCENA-UNNE). Casilla de Correo 291, 3400, Corrientes, Argentina. scgnaed@hotmail.com

\section{KAREN ADAMI-RODRIGUES}

Núcleo de Estudos em Paleontologia e Estratigrafia, Centro das Engenharias, Universidade Federal de Pelotas. Rua Xavier Ferreira, 2, 96010-440, Pelotas, RS, Brasil.karen.adami@gmail.com

\begin{abstract}
NEW WOOD RECORDS OF THE MIOCENE OF THE SOLIMÕES FORMATION, ACRE BASIN, AMAZONIA, BRAZIL. New fossil wood records associated to the families Lecythidaceae, Calophyllaceae, Combretaceae and Arecaceae for the Miocene of the Solimões Formation, Acre Basin, Brazil, are described. The specimens have been collected on the banks of the Juruá and Envira rivers. The main anatomical characters that allowed relating the specimens to these families are tangential diameter and distribution of vessels per mm ${ }^{2}$, parenchyma type, intravascular pits and types and sizes of rays. It is the first record of Carinianoxylon brasiliense Selmeier, Calophyloxylon eoionophyllum Prakash and Awasthi, Terminalioxylon erichensii Mussa and Palmoxylon Schenk for formation; in addition, a new species for the genus Lecythioxylon Milanez is described. Systematic comparisons have been made with the other fossil records of these families in other Gondwana formations. The paleoflora of the Solimões Formation analyzed here shows a great richness of taxonomic groups, reason why this work provides new and important data for the knowledge of the paleoflora of the Amazon region.
\end{abstract}

Key words: Angiosperms, Miocene, Solimões Formation, Amazon.

RESUMO - Novos registros de lenhos fósseis atribuídos às famílias Lecythidaceae, Calophyllaceae, Combretaceae e Arecaceae são descritos para o Mioceno da Formação Solimões, Bacia do Acre, Brasil. Os exemplares foram coletados as margens dos rios Juruá e Envira. As principais características anatômicas que permitiram relacionar os exemplares a estas famílias são: diâmetro tangencial e distribuição dos vasos por $\mathrm{mm}^{2}$, tipo de parênquima, pontuações intervaculares, tipos e tamanhos de raios. Se registra pela primeira vez Carinianoxylon brasiliense Selmeier, Calophyloxylon eoionophyllum Prakash \& Awasthi, Terminalioxylon erichensii Mussa e Palmoxylon Schenk, para a Formação Solimões. Além disso, é proposta uma nova espécie para o gênero Lecythioxylon Milanez para a formação. As comparações sistemáticas foram realizadas com outros registros fósseis destas famílias para outras formações do Gondwana. A paleoflora da Formação Solimões analisada até o momento mostra uma grande riqueza de grupos taxonômicos, pelos quais este trabalho contribui com novos e importantes dados para o conhecimento da paleoflora da região Amazônica.

Palavras-chave: Angiospermas, Mioceno, Formação Solimões, Amazônia.

\section{INTRODUCCIÓN}

La región Amazónica posee abundantes afloramientos que contienen fósiles de plantas y de vertebrados. El primer trabajo relacionado al estudio de las maderas fósiles de la Cuenca de Acre corresponden a afloramientos del Rio Juruá, realizado por Mussa (1959), donde se describen ejemplares pertenecientes a las familias Sapindaceae, Lecythidaceae y LeguminosaeCaesalpinoideae. Machado et al. (2012) describen nuevos materiales para la Cuenca de Acre y los relacionan con las familias Leguminosae, Lythraceae y Myrtaceae, pero sin afinidad específica. Posteriormente, Kloster et al. (2013, 2015) registran nuevas Fabaceae para el Río Juruá y Kloster (2015) describe en su trabajo de tesis doctoral, la presencia de 11 familias y 15 especies de angiospermas para los ríos Juruá y Envira. Todavía es necesario continuar con el estudio de estos materiales para profundizar el conocimiento de la paleoflora que originó a la actual selva Amazónica.

En esta contribución se describen Carinianoxylon brasiliense Selmeier, Calophyloxylon eoionophyllum Prakash \& Awasthi, Terminalioxylon erichensii Mussa y Palmoxylon Schenk y se describe una nueva especie asignada al género Lecythioxylon Martinez, constituyendo el primer registro para la Formación Solimões. 


\section{ÁREA DE ESTUDIO}

La Cuenca de Acre se encuentra en su mayor parte recubierta por la Formación Solimões (Figura 1A), que a su vez está compuesta, en la parte superior de la sección por areniscas consolidadas con pequeños granos blancos subangulares a sub-redondeados de finos a gruesos (Caputo, 1984), seguidas por areniscas, arcillas, concreciones calcáreas, y escaso materiale carbonizado (turba y lignito), ocurren también limolitas, calizas limosas-arcillosa, areniscas con hierro, conglomerados, lutitas, limolitas, gipsítas y hierro, concentraciones de pirita y gran cantidad de fragmentos fósiles de vertebrados (Radambrasil, 1978; Hoorn, 1993). Las maderas petrificadas proceden de diversos localidades de la
Formación Solimões que afloran en las márgenes de los ríos Juruá y Envira, (Figura 1A).

Las maderas analizadas en esta contribución (Figura 1C) proceden de la localidad afloramiento PRE06 en el río Envira (Figura 1B). La Figura 2 muestra en el perfil estratigráfico el nivel fosilífero donde fueron hallados los troncos fósiles en niveles conglomerádicos; por encima de este estrato se depositaron niveles arcillosos portadores de impresiones foliares.

El perfil estratigráfico presenta aproximadamente 6 $\mathrm{m}$ de altura. La base está constituida por $1 \mathrm{~m}$ de arcillita gris, seguido por una capa de aproximadamente $0,30 \mathrm{~m}$ de conglomerado con gravas y gránulos mal seleccionados, subangulosos, grisáceos con matriz arenosa. A continuación
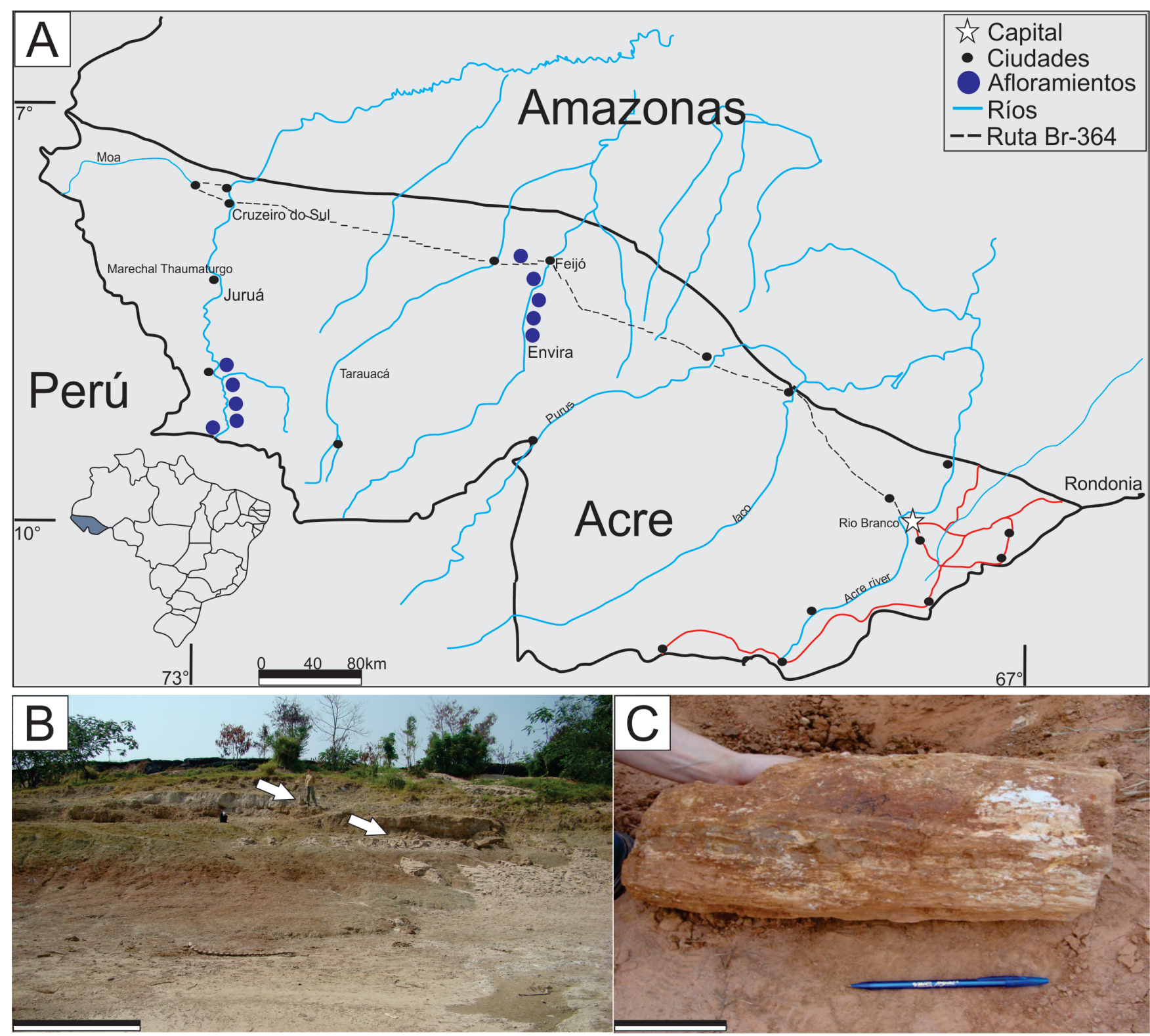

Figura 1. A, mapa de localización geográfica de las localidades donde se coleccionaron maderas fósiles en los ríos Juruá y Envira. B, en detalle la localidad (PRE 06) río Envira, las flechas muestran en el nivel fosilífero donde se hallaron las maderas. $\mathbf{C}$, foto de detalle de una muestra de leño fósil.

Figure 1. A, geographic location map of the localities where fossil woods were collected in the Juruá and Envira rivers. B, in detail the locality (PRE 06) Envira River, the arrows show the fossiliferous level where the samples are collected. C, detail photo of a fossil wood sample. 
$0,30 \mathrm{~m}$ de arcillita gris clara con muscovita y estructura maciza, seguida por una capa de $2 \mathrm{~m}$ de arenisca fina con estructura maciza y la parte superior está formada por casi 2 $\mathrm{m}$ de arcilla (Figura 2).

La Formación Solimões fue depositada principalmente entre el final del Mioceno y el inicio del Plioceno (Westaway, 2006). El origen fluvial/lacustre para los sedimentos de esta formación es sostenido por Latrubesse et al. (1997) y Westaway (2006). Gross et al. (2011) postularon que desde el Mioceno en la Amazonia Occidental existieron extensas zonas de humedales. Los depósitos de la parte superior del Solimões (bioestratigráficamente datados como Mioceno tardío) representan depósitos fluviales probablemente de sistemas de ríos anastomosados, con cuerpos de arenas que se formaron al interior de canales activos, deltas, canales abandonados, llanuras de inundación y paleosuelos. Todas estas condiciones se presentaron en sistemas lacustres localmente restringidos a lagos. Los moluscos y ostrácodos que se han encontrado son exclusivamente de aguas dulces y descartan completamente la ingresión de aguas marinas durante el Mioceno tardío, así como la existencia de paleolagos, como el lago Pebas (Latrubesse et al., 2010; Jaramillo et al., 2011, p. 561-562).

Algunas propuestas bioestratigráficas se basaron en la asociación de mamíferos fósiles. Así, Paula-Couto (1983), afirma que los mamíferos encontrados en Acre indicarían diferentes edades entre el Oligoceno y el Pleistoceno tardío. Otros, propusieron una edad entre el Plioceno tardío y el Pleistoceno (Projeto Radambrasil, 1977) o el Pleistoceno tardío (Frailey et al., 1988; Kronberg et al., 1991). Mientras que para Ranzi (2000), los fósiles de vertebrados de las diversas localidades del Sudoeste del Amazonas brasileño indicarían una edad entre el Eoceno y el Pleistoceno tardío. Sin embargo, Latrubesse (1992) y Latrubesse et al. (1997) consideraron que la fauna fósil de esta región corresponde a la edad mamífero Huayqueriense, posiblemente alcanzando una edad Montehermosense (Mioceno tardío-Plioceno) (Ribeiro et al., 2013, p. 210).

Posteriormente, Latrubesse et al. $(2007,2010)$ consideraron que los vertebrados fósiles de la Formación Solimões pertenecen solo al Mioceno tardío, cuya edad sería correlacionable con la edades Huayqueriense/"Mesopotamiense" (9-6,5 Ma, Cione et al., 2000). De acuerdo con Negri et al. (2010), la fauna correspondería al Mioceno tardío. Sin duda, la mayor parte de la fauna de mamíferos encontrada a lo largo del Río Acre y de las carreteras presenta similitudes con aquellas de edades Huayqueriense/“Mesopotamiense"-Montehermosense; pero es relevante observar que no ocurre lo mismo sobre el Río Juruá, el cual presenta particularidades distintas a lo largo de su curso próximo al Perú (Ribeiro et al., 2013, p. 210).

\section{MATERIAL Y MÉTODOS}

Los ejemplares han sido coleccionados en la Formación Solimões en los márgenes de los ríos Juruá y Envira, Cuenca de Acre, Amazonia, Brasil (Figura 1). Para su análisis, fueron realizados cortes petrográficos en tres planos anatómicos: transversal, longitudinal radial y longitudinal tangencial (CT,

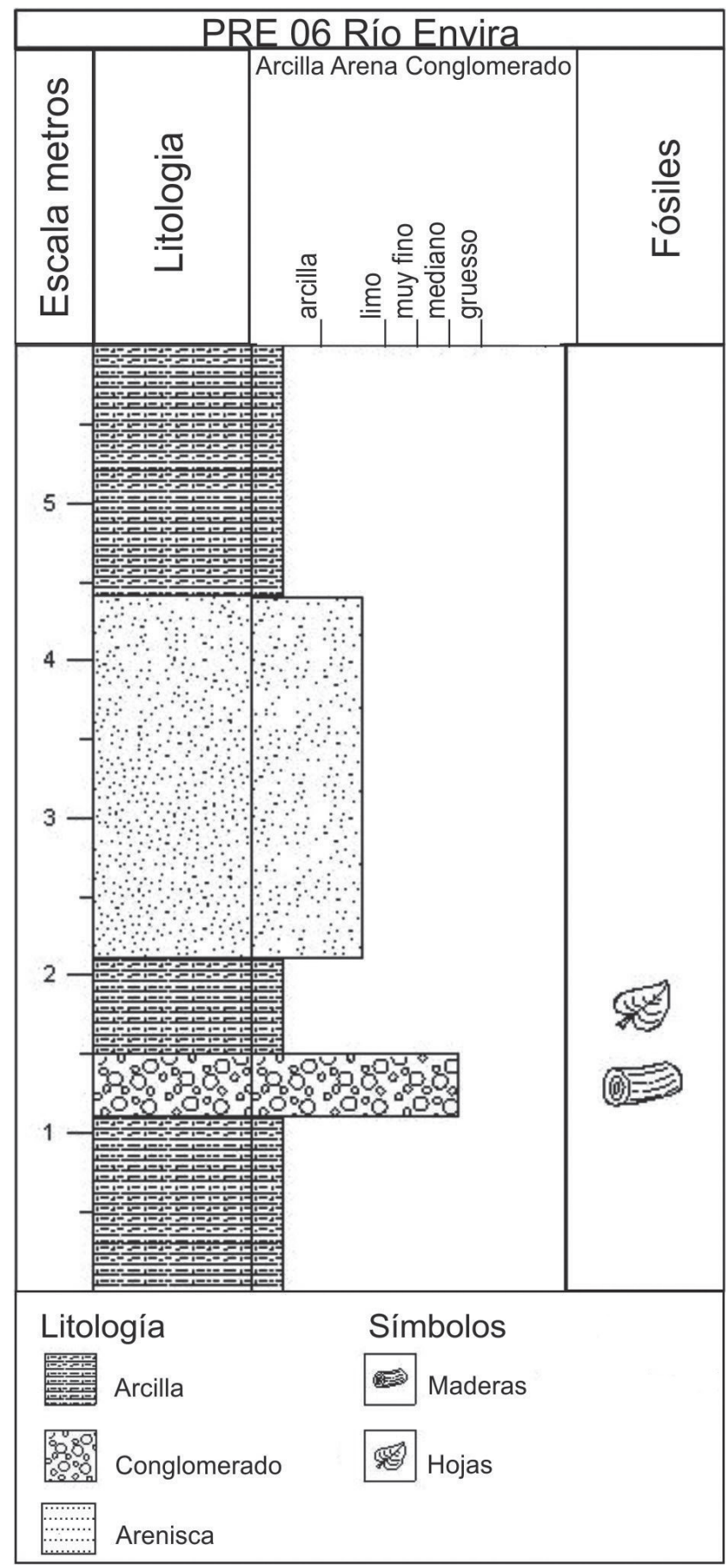

Figura 2. Perfil estratigráfico de la localidad fosilífera (PRE 06 Río Envira).

Figure 2. Stratigraphic profile of the fossiliferous locality (PRE 06 Envira River).

CLR, CLT). El material fue observado con un microscopio óptico Leica DM500 con cámara incluida, un microscopio estereoscópico Leitz (LM) y con el microscopio electrónico de barrido modelo Jeol (JSM-580 OLV) de la Universidad Nacional del Nordeste (UNNE), Corrientes, Argentina. Para la observación con microscopio electrónico de barrido (MEB) se utilizó el método de fragmentación y metalización con oro. Los datos cuantitativos dados en las descripciones 
de los ejemplares son promedios de 25 medidas. En todos los casos se cita primero la media y entre paréntesis las medidas mínimas y máximas del rango de distribución. Para realizar las descripciones anatómicas se siguieron diferentes terminologías, propuestas por los glosarios de términos de la Asociación Internacional de Anatomistas de Maderas (IAWA, 1989); Metcalfe \& Chalk (1950) y por Carlquist (2001). También se utilizaron otros glosarios de términos de maderas (Kribs, 1935), las clasificaciones estándar de Chattaway (1932) y las recopilaciones bibliográficas de Gregory (2009).

Para las comparaciones se ha revisado bibliografía de especies actuales y fósiles, de diferentes procedencias, ya sean Amazónicas, o de otras regiones como India y África. Éstas, fueron efectuadas con las descripciones dadas por Metcalfe \& Chalk (1950), Détienne \& Jacquet (1983) y Miller \& Détienne (2001). Se utilizó la base de datos disponibles en internet: InsideWood database (2004 onwards). Se siguió la clasificación sistemática del APG IV (2016). Los mapas de distribución de las familias y géneros fueron tomados de Stevens (2001 onwards, "Angiosperm Phylogeny Website, version 12, july 2012 [and more or less continuously updated since]." http://www.mobot.org/MOBOT/research/APweb/).

\section{SISTEMÁTICA PALEOBOTÁNICA}

Orden ERICALES Bercht. \& J.Presl, 1820
Familia LECYTHIDACEAE Richard, 1825

Carinianoxylon Selmeier, 2003

Especie-tipo. Carinianoxylon brasiliense Selmeier, 2003. Carinianoxylon brasiliense Selmeier, 2003

(Figuras 3-4)

Afinidad botánica. Cariniana Casaretto.

Material estudiado. LPP-CZS 0193 PRE 06. Adicional. LPP-CZS 0081 PRJ 7, 0133 PRJ 8, 0137 PRJ 9.

Procedencia estratigráfica. Formación Solimões.

Procedencia geográfica. Río Envira, Río Juruá, Acre, Brasil. Descripción. Fragmentos de leños de distintos tamaños con estructura secundaria preservada. Los anillos de crecimiento son indistintos o ausentes. La porosidad es difusa. Los vasos tienen un trayecto rectilíneo y no presentan un patrón de distribución. Vasos predominantemente solitarios $(60 \%)$, pero también se observan múltiples radiales de $2(30 \%)$, y $3(10 \%)$ elementos, con un diámetro tangencial promedio de $170 \mu \mathrm{m}(100-265 \mu \mathrm{m})$, y con una densidad promedio de 14 vasos por $\mathrm{mm}^{2}$; con contenido semejante a tilosis de tamaños similares y de contorno oval/circular (Figuras 3A-B, 4A-B). (Figuras 3A-B, 4A-B). Los elementos de vasos son medianos, con una longitud promedio de $485 \mu \mathrm{m}$ (400-650 $\mu \mathrm{m})$, presentan paredes terminales rectilíneas a oblicuas y placas de perforación simples (Figuras 3C, 4A-B). Las puntuaciones intervasculares son circulares, o alargadas $\mathrm{y}$ se disponen desde opuestas a alternas, algunas con aberturas lineales y con un diámetro promedio de $8 \mu \mathrm{m}(6-10 \mu \mathrm{m})$, las más alargadas miden aproximadamente 10 a $15 \mu \mathrm{m}$ (Figuras 4A-D). Las fibras son simples, de sección poligonal, no septadas, con paredes de espesor mediano $(2$ a $6 \mu \mathrm{m})$ y lumen con un diámetro de 8 a $10 \mu \mathrm{m}$ (Figuras $3 \mathrm{~A}-\mathrm{B}, 4 \mathrm{E}$ ). El parénquima axial es apotraqueal tipo reticular en bandas o líneas con 2 a 3 células de alto. (Figuras 3A-D). Los radios son homogéneos con tendencia a heterogéneos, tipo I de Kribs, lineales, compuestos por células procumbentes, son de 1 a 3 seriados, en su mayoría biseriados y triseriados, algunos radios fusionados están presentes, se encuentran en un promedio de 8 (7-10) por mm lineal con una altura promedio de $350 \mu \mathrm{m}(200-800 \mu \mathrm{m})$ y $40 \mu \mathrm{m}(15-60 \mu \mathrm{m})$ de ancho, la altura en número de células es de 13 (8-25) (Figuras 3D-F, $4 \mathrm{~F})$. Las puntuaciones radiovasculares son similares a las intervasculares en forma y disposición (Figura 3G).

\section{Lecythioxylon Milanez, 1935}

Especie-tipo. Lecythioxylon brasiliense Milanez, 1935.

Lecythioxylon enviraense $\mathrm{n}$. $\mathrm{sp}$.

(Figuras 5-6)

Etimología. Referente al Río Envira, que nace en la Sierra de la Contamana, en Perú y baña los estados de Acre y Amazonas, en Brasil.

Afinidad botánica. Lecythidaceae, Lecythis zabucajo Aublet. Holotipo. LPP-CZS 0217, PRE 06.

Diagnosis. Growth rings indistinct or absent. Diffuse porous wood without pattern of distribution. Vessels solitary and radial multiples, tylosis present. Simple perforation plates. Intervessel pits medium, alternate to opposite. Vessel-ray pits similar to intervessel. Axial parenchyma apotracheal reticulate forming bands, septate. Simple fibers, non-septate. Rays are homogeneous tending to heterogeneous, formed by procumbent cells, and upright cells, not storied. Crystals and dark resin present in some ray cells.

Diagnosis. Anillos de crecimiento, indistintos o ausentes. Porosidad difusa sin patrón de distribución. Vasos solitarios y múltiples radiales, tilosis presente. Placas de perforación simples. Puntuaciones intervasculares de opuestas a alternas. Puntuaciones radiovasculares similares a las intervasculares. El parénquima axial apotraqueal reticular en bandas, presenta septos. Fibras simples, no septadas. Radios homogéneos con tendencia a heterogéneos, compuestos por células procumbentes y erectas, no estratificados. Cristales y contenido oscuro presente en algunas células de los radios.

Procedencia estratigráfica. Formación Solimões.

Procedencia geográfica. Río Envira, Acre, Brasil.

Descripción. Anillos de crecimiento indistintos o ausentes. La porosidad difusa. Los vasos tienen un trayecto rectilíneo y no presentan un patrón de distribución, presentan contenido semejante a tilosis (Figuras 5A-B, 6A-B). Los vasos son de contorno oval/circular, predominantemente solitarios (60\%) y múltiples radiales de $2(40 \%)$, con un diámetro tangencial promedio de $128 \mu \mathrm{m}(75-200 \mu \mathrm{m})$, con densidad promedio de 9 (4-15) vasos por $\mathrm{mm}^{2}$ y presencia de vasos 

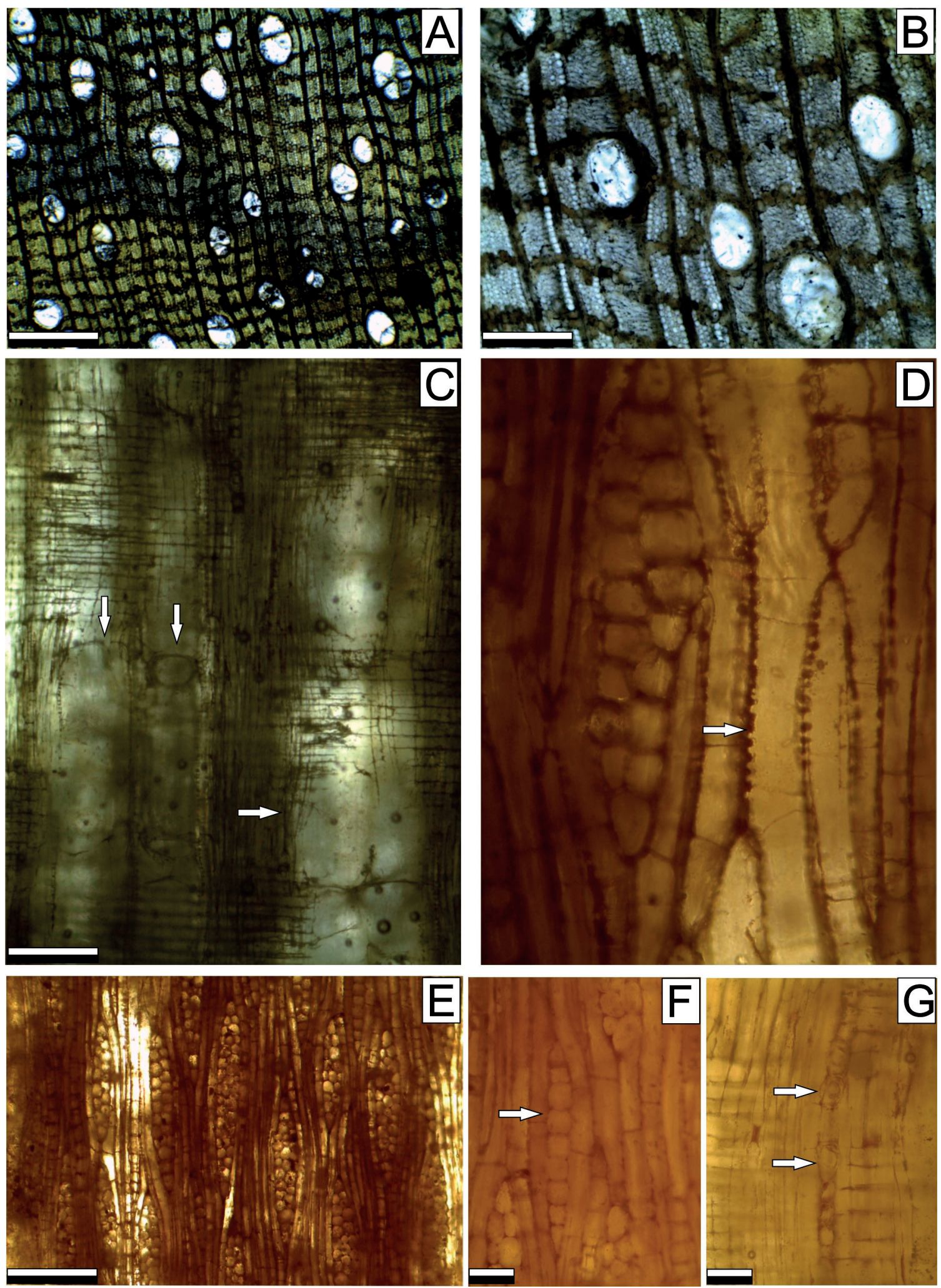

Figura 3. Carinianoxylon brasiliense (LPP-CZS 0193). M.O. A-B, (CT), vasos solitarios y múltiples, vasos con tilosis, parénquima axial apotraqueal reticular. C, (CLR), placas de perforación simples (flechas). D, detalle del parenquima axial (flecha). D-F, (CLT), 5, radios homogéneos 1-3 seriados. F, detalle de un radio uniseriado (flecha). G, serie de cristales en cámaras de parénquima axial (flecha). Abreviaturas en Material y Métodos. Escalas: $\mathrm{A}-\mathrm{B}=200 \mu \mathrm{m} ; \mathrm{C}-\mathrm{E}=100 \mu \mathrm{m} ; \mathrm{F}=50 \mu \mathrm{m}$.

Figure 3. Carinianoxylon brasiliense (LPP-CZS 0193). O.M. A-B, (TS), solitary and multiple vessels, vessels with tilosis, axial reticular apotracheal parenchyma. C, (LRS), simple perforation plates (arrows). D, axial parenchyma detail (arrow). D-F, (LTS), 5, homogeneous rays 1-3 series. $\mathbf{F}$, detail of a uniseriate ray (arrow). G, detail of prismatic crystals in chambered axial parenchyma cells (arrow). Abbreviations in Material and Methods. Scale bars: A-B $=200 \mu \mathrm{m} ; \mathrm{C}-\mathrm{E}=100 \mu \mathrm{m} ; \mathrm{F}=50 \mu \mathrm{m}$. 

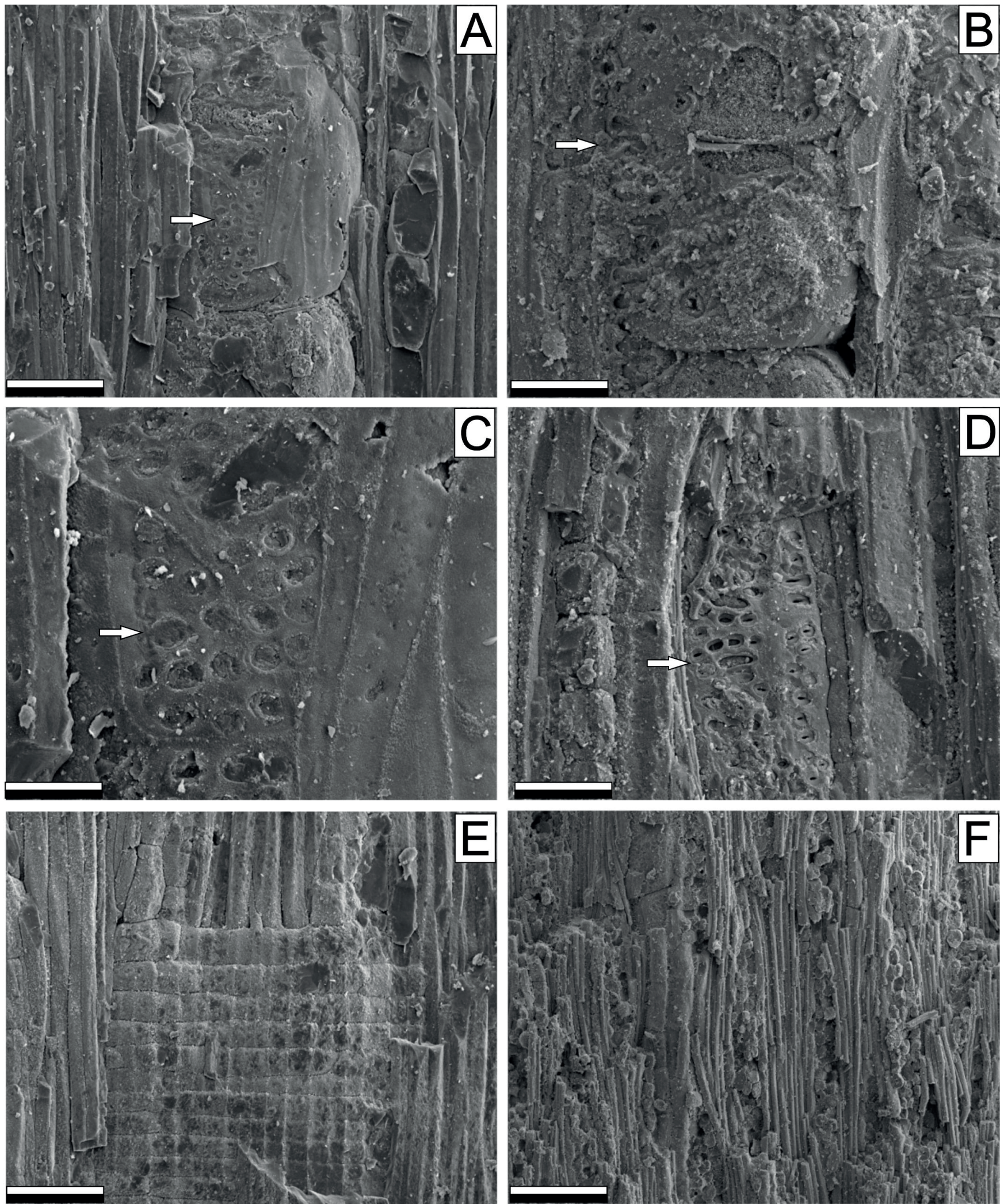

Figura 4. Carinianoxylon brasiliense (LPP-CZS 0193). MEB. A, vasos y puntuaciones intervasculares (flecha). B, placa de perforacion simples (flecha). C-D, puntuaciones intervasculares (flechas). E-F, vista general de un radio y fibras simples, no septadas con puntuaciones simples. Radios 1-3 seriados, homogéneos con tendencia a heterogéneos $(F)$. Abreviatura en Material y Métodos. Escalas: $A-D=50 \mu m ; E-F=100 \mu m$.

Figure 4. Carinianoxylon brasiliense (LPP-CZS 0193). SEM. A, vessels and intervessel pits (arrow). B, simple perforation plate (arrow). C-D intervessel pits (arrows). E-F, general view of a ray and simple fibers, non-septate fibers with simple pits. Rays 1-3 seriate, homogeneous with heterogeneous tendencies $(F)$. Abbreviation in Material and Methods. Scale bars: A-D = 50 $\mu \mathrm{m} ; E-F=100 \mu \mathrm{m}$. 
angostos (Figuras 5A-B, 6A-C). Los elementos de vasos son cortos a medianos, con una longitud promedio de 450 $\mu \mathrm{m}(300-600 \mu \mathrm{m})$, presentan paredes terminales rectilíneas a oblicuas y placas de perforación de tipo simples (Figuras 6A-B), las puntuaciones intervasculares son de opuestas a alternas, ovaladas a circulares, de distintos tamaños y disposición, con aperturas lineales y con diámetro promedio de $10 \mu \mathrm{m}(8-10 \mu \mathrm{m})$ (Figuras 6A-E). Las fibras son simples, de sección poligonal, no septadas, con paredes de espesor mediano $(2$ a $6 \mu \mathrm{m}$ ) y lumen de 8 a $10 \mu \mathrm{m}$ (Figuras 5A-B, $6 \mathrm{~F}-\mathrm{H})$. El parénquima axial apotraqueal es tipo reticular en bandas o líneas con más de 3 células de alto, presenta septos (Figuras 5A-C). Los radios son homogéneos con tendencia a heterogéneos, lineales, compuestos por células procumbentes, son de 1 a 3 seriados, en su mayoría biseriados y triseriados y algunos fusionados, son del tipo I de Kribs y se encuentran en un promedio de $10(7-12)$ por mm lineal con una altura promedio de $360 \mu \mathrm{m}(260-500 \mu \mathrm{m})$ y $40 \mu \mathrm{m}(35-50 \mu \mathrm{m})$ de ancho, la altura en número de células es de 18 (8-30) (Figuras $5 \mathrm{C}-\mathrm{D}, 6 \mathrm{~F}-\mathrm{H}$ ). Las puntuaciones radiovasculares son similares a las intervasculares en forma y disposición. Cristales y contenido oscuro semejante a resina presente en algunas células de los radios (Figura 5D).

Observaciones. De acuerdo con Metcalfe \& Chalk (1950), la familia Lecythidaceae es un grupo homogéneo, caracterizado por vasos solitarios y múltiples radiales, algunas veces formando "clusters" o agrupados, placas de perforación exclusivamente simples, puntuaciones intervasculares alternas, y las radiovasculares pueden tener distintos tamaños, parénquima axial apotraqueal en bandas (reticulado), fibras simples, radios 2-3 seriados homogéneos a heterogéneos, cristales en cámaras de parénquima axial, principalmente en los géneros americanos. Esta combinación de caracteres permitió incluir los ejemplares analizados en la familia Lecythidaceae.

Según Détienne \& Jacquet (1983) las características de Cariniana son: vasos solitarios y múltiples radiales de 2 y 3 , con una densidad de 5-10 por $\mathrm{mm}^{2}$, diámetro tangencial de 120-200 $\mu \mathrm{m}$, placas de perforación simples, puntuaciones intervasculares de 7-11 $\mu \mathrm{m}$, parénquima reticular con 1-2 células de alto, radios homogéneos a heterogéneos, la mayoría biseriados (1-3) seriados, de 7-9 por mm lineal, puntuaciones radiovasculares similares a las intervasculares, fibras simples y cristales en cámaras del parénquima axial presentes caracteres que comparte con el género fósil Carinianoxylon Selmeier.

De acuerdo con Détienne \& Jacquet (1983) las características de Lecythis son: vasos solitarios y múltiples radiales de 2 y 3 , con una densidad de 3-4 por $\mathrm{mm}^{2}$, diámetro tangencial de 180-240 $\mu \mathrm{m}$, placas de perforación simples, puntuaciones intervasculares de $7-10 \mu \mathrm{m}$, parénquima reticular con 1-2 células de alto, en algunas especies bandas más largas de 3-8 células de alto, radios homogéneos a heterogéneos 2-4 seriados, de 7-11 por mm lineal, puntuaciones radiovasculares similares a las intervasculares, fibras simples y cristales en cámaras presente en algunas especies, rasgos anatómicos coincidentes con el taxón fósil Lecythioxylon.
Por la homogeneidad presentada por los caracteres anatómicos de la madera de las Lecythidaceae (Metcalfe \& Chalk, 1950), los ejemplares analizados en esta contribución son comparados con especies actuales de la región en las Tablas 1 y 2.

Comparaciones con fósiles. Los registros de la familia Lecythidaceae datan desde el Oligoceno-Eoceno y son escasos los fósiles de maderas de Lecythidaceae existentes. Las especies descriptas son: Lecythioxylon brasiliensi Milanez, 1935 y Lecythioxylon milanezzi Mussa, 1959 de Brasil, Barringtonioxylon arcotense Awasthi, 1969a y Careyoxylon pondicherriense Awasthi, 1969a de Asia, Carinianoxylon brasiliensi Selmeier, 2003 de Brasil, cf. Cariniana sp. y cf. Eschweilera sp. Pons \& De Francheschi, 2007 y Cariniana valverdei Woodcock et al., 2017 de Perú.

En este trabajo se comparó Carianoxylon brasiliensi y Lecythioxylon milanezzi con las especies de Barringtonioxylon arcotense, Careyoxylon pondicherriense y Cariniana valverdei, ambos se distinguen de los ejemplares estudiados por la densidad de vasos por $\mathrm{mm}^{2}$, por el tipo y distribución del parénquima axial, la seriación y tipos de radios y ausencia o presencia de cristales en cámaras del parénquima axial (Tabla 1).

Además, cuando se compara Lecythioxylon brasiliensi y Lecythioxylon milanezzi, ambos del Neógeno de Brasil, resulta que el ejemplar LPP-CZS 0217 se diferencia de ambos por presentar mayor densidad de vasos por $\mathrm{mm}^{2}$ y mayor cantidad de parénquima axial, justificando así la creación de una nueva especie fósil, Lecythioxylon enviraense $\mathrm{n}$. sp. (Tabla 1).

Comparaciones con actuales. Actualmente la familia Lecythidaceae posee 25 géneros y 315 especies. Se encuentra distribuida mayormente en los neotrópicos, mientras otros géneros están restringidos a los trópicos este y oeste de África, Madagascar, Mauritius y norte tropical de Asia al norte de Australia (Lens et al., 2007) (Figura 12A).

Lecythidaceae está subdividida en cinco subfamilias: Scytopetaloideae, Foetidioideae, Planchonioideae y de las cuales dos, (Lecythioideae y Napoleonaeoideae), se encuentran en América (Mori \& Prance, 1999; Lens et al., 2007). Las Lecythidaceae representan un importante grupo arbóreo, propio de bosques tropicales y tierras húmedas, correspondiendo a árboles desde pequeño a gran porte, como Bertholletia excelsa por ejemplo, conocida popularmente como "la reina de la selva" que puede alcanzar hasta 50-60 $\mathrm{m}$ de altura. La subfamilia Lecythioideae es la más abundante en el Amazonas y se encuentra representada por los géneros: Allantoma, Bertholletia, Cariniana, Corythophora, Couratari, Couroupita, Eschweilera, Gustavia, Grias y Lecythis. Excepto Asteranthos, representada por la especie $A$. brasilienses, la cual se ubica en la subfamilia Napoleonaeoideae (Aristeguieta, 2003).

Se destacan los trabajos de Zeeuw $(1990,1992)$ donde, además de descripciones, elaboró claves de identificación incluyendo sólo material correspondiente a esta familia. Las Lecythidaceae son árboles tropicales de planicie y que alcanzaron su mayor diversidad de especies en el neotrópico. En Sudamérica, se presenta mayormente diversificada en los 

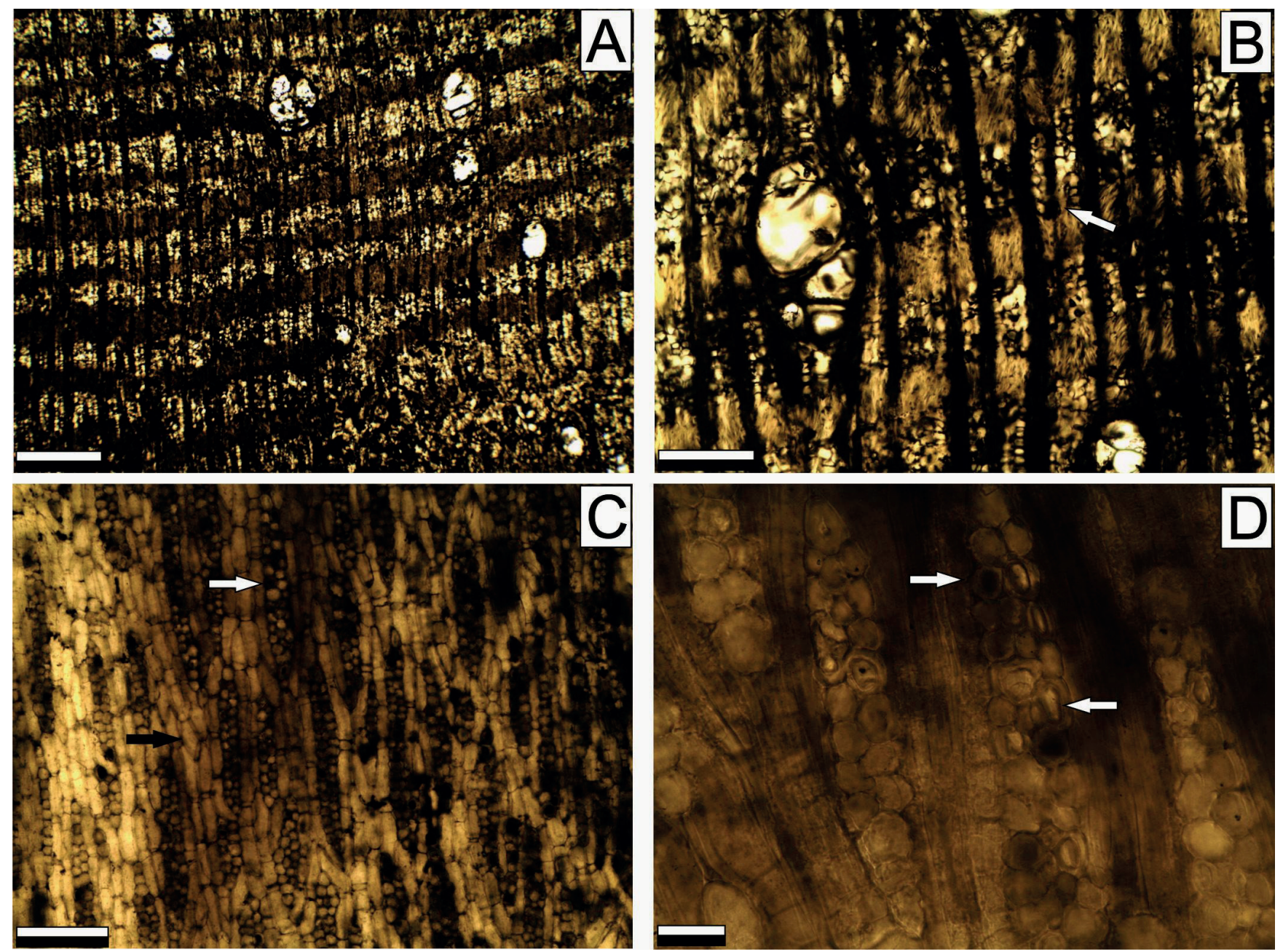

Figura 5. Lecythioxylon enviraense n. sp. (LPP-CZS 0217). M.O. A-B, (CT), vasos solitarios y múltiples radiales, vasos con tilosis/resina. B, el parénquima axial apotraqueal reticular en bandas, presenta septos (flecha). C, (CLR), detalle del parenquima septado (flecha negra) y radio (flecha blanca). D, (CLT), radios homogéneos, las flechas indican presencia de cristales y resina. Abreviaturas en Material y Métodos. Escalas: $A, C=100 \mu \mathrm{m} ; \mathrm{B}, \mathrm{D}=50 \mu \mathrm{m}$.

Figure 5. Lecythioxylon enviraense n. sp. (LPP-CZS 0217). O.M. A-B, (TS), solitary and multiple vessels, vessels with tilosis/resin. B, axial apotracheal parenchyma reticulate in bands, septate (arrow). C, (LRS), detail of the septate axial parenchyma (black arrow) and rays (white arrow). D, (LTS), homogeneous rays, arrows indicate presence of crystals and resin content. Abbreviations in Material and Methods. Scale bars: $A, C=100 \mu \mathrm{m} ; B, D=50 \mu \mathrm{m}$.

hábitats de selva del Amazonas y Guayanas donde más de 50\% las especies son endémicas del Amazonas (Mori, 1990). En el mismo trabajo, Mori observó que Cariniana se distribuye principalmente en el Oeste del Amazonas, mientras Couratari, Eschweilera y Lecythis son más diversas en la parte central del Amazonas y Guayanas.

León (2008), destaca la importancia del conocimiento de la anatomía de la madera de Lecythidaceae, por ser un grupo taxonómico con una importante representación en el país, especialmente en el Amazonas, y que poco se conoce de la anatomía de la madera de las especies que crecen en Brasil, lo que dificulta la identificación de especies.

Los especímenes fósiles también fueron comparados con las especies actuales: Bertholletia excelsa Humb, Couratari guianensis Aublet, Cariniana multiflora Ducke, Coroupita guianensis Aublet, Eschweilera alata Smith, y Lecythis zabucajo Aublet que habitan la región amazónica actualmente
(Tabla 2). La especie más semejante con el ejemplar LPP-CZS 0193 es Cariniana multiflora Ducke y el ejemplar LPP-CZS 0217 afín a especie Lecythis zabucajo Aubl. (Tabla 2).

Orden MALPIGHIALES Juss. ex Bercht. \& J.Presl, 1820

Calophylloxylon Lakhanpal \& Awasthi, 1965

Especie-tipo. Calophylloxylon indicum Lakhanpal \& Awasthi, 1965

Calophylloxylon eoinophyllum Prakash \& Awasthi, 1971 (Figuras 7-8)

Afinidad botánica. Calophyllum L.

Material estudiado. LPP-CZS 0194 PRE 06.

Procedencia estratigráfica. Formación Solimões. 
Tabla 1. Comparación entre maderas fósiles de Lecythidaceae.

Table 1. Comparison among Lecythidaceae fossil woods.

\begin{tabular}{|c|c|c|c|c|c|}
\hline Especies & Vasos & Parénquima axial & Radios & Cristales & Otro \\
\hline $\begin{array}{l}\text { Barringtonioxylon arcotense } \\
\text { Awasthi, } 1969 \mathrm{a}\end{array}$ & $8-16 \mathrm{~mm}^{2}$ & $\begin{array}{c}\text { paratraqueal y } \\
\text { apotraqueal difuso }\end{array}$ & $\begin{array}{l}6-8 \mathrm{~mm} \\
\text { 1-8 seriados homogéneos/ } \\
\text { heterogéneos }\end{array}$ & ausentes & $\begin{array}{l}\text { tilosis y } \\
\text { sílice }\end{array}$ \\
\hline $\begin{array}{l}\text { Careyoxylon pondicherriense } \\
\text { Awasthi, } 1969 \text { a }\end{array}$ & $8-15 \mathrm{~mm}^{2}$ & $\begin{array}{l}\text { paratraqueal espaciado y } \\
\text { apotraqueal abundante } \\
1-6 \text { células de alto }\end{array}$ & $\begin{array}{c}9-14 \mathrm{~mm} \\
1-4 \text { seriados } \\
\text { homogéneos/heterogéneos }\end{array}$ & ausentes & tilosis \\
\hline $\begin{array}{l}\text { Carinianoxylon brasiliensi } \\
\text { Selmeier, } 2003\end{array}$ & $\begin{array}{c}7-14 \mathrm{~mm}^{2} \\
170 \mu \mathrm{m}\end{array}$ & reticular & $\begin{array}{c}8-11 \mathrm{~mm} \\
1-3 \text { seriados } \\
\text { homogéneos/heterogéneos }\end{array}$ & presente & tilosis \\
\hline $\begin{array}{l}\text { Lecythioylon brasiliensi } \\
\text { Milanez, } 1935\end{array}$ & $4-5 \mathrm{~mm}^{2}$ & $\begin{array}{l}\text { en líneas de } 1-2 \\
\text { células de alto }\end{array}$ & $\begin{array}{c}7-12 \mathrm{~mm} \\
1-3 \text { seriados } \\
\text { homogéneos/heterogéneos }\end{array}$ & presente & $\longrightarrow$ \\
\hline $\begin{array}{l}\text { Lecythioxylon } \\
\text { milanezzi } \\
\text { Mussa, } 1959\end{array}$ & $4-5 \mathrm{~mm}^{2}$ & $\begin{array}{l}\text { en líneas regulares } \\
\text { de } 1-2 \text { células de alto }\end{array}$ & $\begin{array}{c}9-12 \mathrm{~mm} \\
1-3 \text { seriados } \\
\text { homogéneos/heterogéneos }\end{array}$ & presente & tilosis \\
\hline $\begin{array}{l}\text { Cariniana valverdei } \\
\text { Woodcock et al., } 2017\end{array}$ & $7 \mathrm{~mm}^{2}$ & $\begin{array}{c}\text { paratraqueal escasso y } \\
\text { apotraqueal } 1-3 \text { células de alto }\end{array}$ & $\begin{array}{c}5 \mathrm{~mm} \\
1-4 \text { seriados } \\
\text { homogéneos/heterogéneos }\end{array}$ & presente & $\begin{array}{l}\text { tilosis y } \\
\text { sílice }\end{array}$ \\
\hline $\begin{array}{l}\text { Carinianoxylon brasiliensi } \\
\text { LPP-CZS } 0193 \\
\text { Este trabajo }\end{array}$ & $\begin{array}{c}7-14 \mathrm{~mm}^{2} \\
170 \mu \mathrm{m}\end{array}$ & $\begin{array}{l}\text { apotraqueal reticular en bandas } \\
\text { regulares hasta } 3 \text { células de alto }\end{array}$ & $\begin{array}{c}8 \mathrm{v} 10 \mathrm{~mm} \\
1-3 \text { seriados } \\
\text { homogéneos/heterogéneos }\end{array}$ & presente & tilosis \\
\hline $\begin{array}{l}\text { Lecythioxylon enviraense } \\
\text { n. sp. } \\
\text { LPP-CZS } 0217 \\
\text { Este trabajo }\end{array}$ & $\begin{array}{l}4-15 \mathrm{~mm}^{2} \\
128 \mu \mathrm{m}\end{array}$ & $\begin{array}{l}\text { apotraqueal reticular } \\
\text { en bandas regulares con } \\
\text { más de } 3 \text { células de alto }\end{array}$ & $\begin{array}{c}7-12 \mathrm{~mm} \\
1-3 \text { seriados } \\
\text { homogéneos/heterogéneos }\end{array}$ & no observado & tilosis \\
\hline
\end{tabular}

Tabla 2. Comparación de los ejemplares estudiados con especies actuales de Lecythidaceae.

Table 2. Comparison among studied species and extant species of Lecythidaceae.

\begin{tabular}{|c|c|c|c|c|}
\hline Especies & Vasos & Parénquima axial & Radios & Cristales \\
\hline Bertholletia excelsa Humb & $\begin{array}{l}\text { hasta } 5 \\
500 \mu \mathrm{m}\end{array}$ & $\begin{array}{l}\text { reticulado con } 5 \\
\text { células de alto }\end{array}$ & $\begin{array}{c}5-12 \mathrm{~mm} \\
1-3 \text { seriados } \\
\text { homogéneos/heterogéneos }\end{array}$ & presente \\
\hline Cariniana multiflora Ducke & $\begin{array}{c}5-10 \\
120-160 \mu \mathrm{m}\end{array}$ & $\begin{array}{l}\text { reticulado } 1-2 \\
\text { células de alto }\end{array}$ & $\begin{array}{c}7-9 \mathrm{~mm} \\
2-3 \text { seriados }\end{array}$ & presente \\
\hline Couratari guianensis Aublet & $\begin{array}{c}2-4 \\
200 \mu \mathrm{m}\end{array}$ & $\begin{array}{l}\text { reticulado con } \\
4 \text { células }\end{array}$ & $\begin{array}{c}6-8 \\
1-4 \text { seriados }\end{array}$ & presente \\
\hline Coroupita guianensis Aublet & $\begin{array}{c}2-5 \\
180 \mu \mathrm{m}\end{array}$ & $\begin{array}{l}\text { reticulado con } \\
3 \text { a } 8 \text { células de alto }\end{array}$ & $\begin{array}{c}\text { 1-4 seriados } \\
\text { homogéneos/heterogéneos }\end{array}$ & presente \\
\hline Eschweilera alata Smith & $\begin{array}{c}3-4 \\
185 \mu \mathrm{m}\end{array}$ & $\begin{array}{l}\text { reticulado } 1-2 \\
\text { células de alto }\end{array}$ & $\begin{array}{c}12 \mathrm{~mm} \\
1-3 \text { seriados } \\
\text { homogéneos/heterogéneos }\end{array}$ & - \\
\hline Lecythis zabucajo Aublet & $\begin{array}{c}4-7 \\
200 \mu \mathrm{m}\end{array}$ & $\begin{array}{l}\text { reticulado } 3-6 \\
\text { células de alto }\end{array}$ & $\begin{array}{c}6-10 \\
1-3 \text { seriados } \\
\text { homogéneos a heterogéneos }\end{array}$ & presente \\
\hline $\begin{array}{l}\text { Carinianoxylon brasiliensi } \\
\text { LPP-CZS } 0193 \\
\text { (Este trabajo) }\end{array}$ & $\begin{array}{c}7-14 \\
170 \mu \mathrm{m}\end{array}$ & $\begin{array}{l}\text { reticular en bandas regulares } \\
\text { hasta } 3 \text { células de alto }\end{array}$ & $\begin{array}{c}8-10 \\
1-3 \text { seriados } \\
\text { homogéneos/ heterogéneos }\end{array}$ & presente \\
\hline $\begin{array}{l}\text { Lecythioxylon enviraense } \mathrm{n} . \mathrm{sp} . \\
\text { LPP-CZS } 0217 \text { (Este trabajo) }\end{array}$ & $\begin{array}{c}4-15 \\
128 \mu \mathrm{m}\end{array}$ & $\begin{array}{l}\text { reticular en bandas regulares } \\
\text { con más de } 3 \text { células de alto }\end{array}$ & $\begin{array}{c}7-12 \\
1-3 \text { seriados } \\
\text { homogéneos/ heterogéneos }\end{array}$ & presente \\
\hline
\end{tabular}



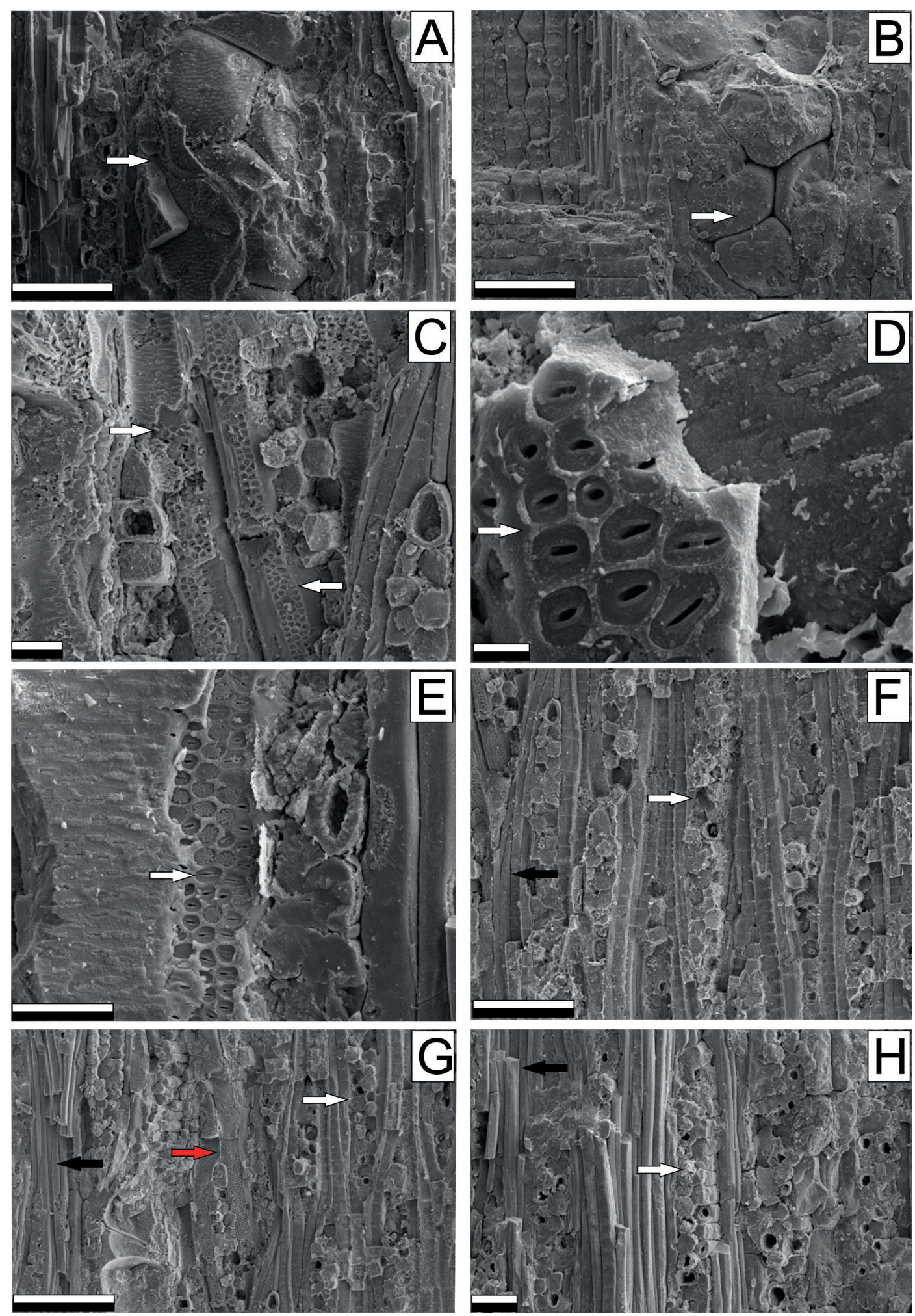

Figura 6. Lecythioxylon enviraense n. sp. (LPP-CZS 0217). MEB. A-B, vasos y pared interna de los vasos con puntuaciones intervasculares y tilosis (flecha). C, detalle de presencia de vasos angostos. D-E, detalle de las puntuaciones intervasculares alternas, com apertura linear (flechas). F-H, fibras simples, no septadas con puntuaciones simples (flechas negras). F-H, radios 1-3 seriados homogéneos/heterogéneos (flechas blancas), detalle de un vaso angosto en G (flecha roja). Abreviatura en Material y Métodos. Escalas: A-D = 50 $\mu \mathrm{m} ; \mathrm{E}, \mathrm{G}-\mathrm{H}=75 \mu \mathrm{m}$; $\mathrm{F}=100 \mu \mathrm{m}$.

Figure 6. Lecythioxylon enviraense n. sp. (LPP-CZS 0217). SEM. A-B, vessels and internal wall intervessel pits and tilosis (arrow). C, detail of narrow vessels. D-E, detail of alternate intervessel pits, with linear aperture (arrows). F-H, simple, non-septate fibers with simple pits (black arrows). $\mathbf{F}-\mathbf{H}$, rays $1-3$ seriate, homogeneous/heterogeneous (white arrows), detail of a narrow vessel in $\mathrm{G}$ (red arrow). Abbreviation in Material and Methods. Scale bars: $A-D=50 \mu \mathrm{m} ; E, G-H=75 \mu \mathrm{m} ; \mathrm{F}=100 \mu \mathrm{m}$. 
Procedencia geográfica. Rio Envira, Acre, Brasil.

Descripción. Fragmento de madera con xilema secundario preservado. Los anillos de crecimiento son indistintos o ausentes. La porosidad es difusa. Los vasos tienen un trayecto levemente sinuoso y presentan patrón de distribución diagonal. Los vasos son de contornos oval/circular, exclusivamente solitarios con un diámetro tangencial de $220 \mu \mathrm{m}$ (150-280 $\mu \mathrm{m}$ ), y una densidad promedio de 8 (6-11) por $\mathrm{mm}^{2}$ (Figuras 7A-D, 8A-B). Los elementos de vasos son cortos, con una longitud promedio de $663 \mu \mathrm{m}(360-800 \mu \mathrm{m})$ (Figuras 7A-C, $8 \mathrm{~A})$. Las placas de perforación son simples, puntuaciones intervasculares no se observan porque sobre los vasos se encuentran muchas traqueidas vasculares/vasicéntricas. Las traqueidas vasicéntricas poseen un diámetro de aproximadamente $22 \mu \mathrm{m}$, lumen de $14 \mu \mathrm{m}$ (Figuras 7D, 8BE). Parénquima axial apotraqueal en bandas/líneas irregulares con 2 a 4 células de alto (Figuras 7A-B). Fibrotraqueidas con puntuaciones areoladas, lumen con un diámetro de $10 \mu \mathrm{m}$ (Figuras 7D, 8F-G). Radios heterogéneos, aproximadamente 9 (5-10) por mm lineal, exclusivamente uniseriados tipo III de Kribs, algunos pocos pueden ser parcialmente biseriados, formados por células cuadradas o erectas, promedio de 12 células de altura, $275 \mu \mathrm{m}(125-421 \mu \mathrm{m})$ de alto y ancho de $17 \mu \mathrm{m}(14-27 \mu \mathrm{m})$ (Figuras 7E-F, 8H). Las puntuaciones radiovasculares no son observables por la presencia de las traqueidas vascuçares/vasicéntricas. Presencia de cristales prismáticos en el parénquima axial.

Observaciones. Según Metcalfe \& Chalk (1950), los caracteres anatómicos de la madera que caracterizan Calophyllaceae son: vasos exclusivamente solitarios, con patrón de disposición diagonal, placas de perforación simples, puntuaciones intervasculares alternas, las radiovasculares alargadas, miembros de vasos de tamaño medianos. Parénquima axial paratraqueal, difuso y en bandas. Radios heterogéneos, 1-3 seriados. Fibras de tamaño mediano con puntuaciones simples o areoladas. Traqueidas vasicéntricas presentes. Canales intercelulares presentes ocasionalmente en los radios.

El género Calophyllum es monotípico según el APG III (2009), incluido anteriormente en la familia Clusiaceae, pero actualmente pertenece a la familia Calophyllaceae. El género Calophyllum tiene distribución neotropical, desde México, Panamá, Bolivia, Ecuador, Guayanas, Perú, Venezuela y Brasil (Figura 12B). En Brasil la especie se distribuye por todo el país. En el Amazonas habitan desde las llanuras de inundación hasta bosques de tierra firme. Según Barros \& Callado (1997), son de hábito arbóreo/arbustivo de gran porte, y pueden medir desde 20 hasta $45 \mathrm{~m}$. Es una especie bastante comercial, su madera es utilizada en la fabricación de muebles y carpintería en general e incluso como biocombustible.

Comparaciones con fósiles. De acuerdo con el listado de Gregory (2009) existen ocho especies fósiles de Calophyllum: de Asia: Calophyllum cuddalorense Lakhanpal \& Awasthi, 1964, Calophyllum indicum Lakhanpal \& Awasthi, 1964, Calophyllum eoinophyllum Prakash, 1966, Calophyllum intermedium Müller-Stoll \& Mädel, 1986, Calophyllum dharmendrae Bande \& Prakash, 1980 y Calophyllum gogalacherraensis Prakash, Lalitha \& Tripathi, 1994; de
África: Calophyllum garcinioides Lemoigne, 1978, y para Sudamérica Pons \& De Francheschi (2007), identifican como cf. Calophyllum sp. a ejemplares del Mioceno de la Formación Pebas de Perú. En la Tabla 3 se compara estas especies fósiles con el material analizado y muestra que es similar en cuanto a la densidad de vasos por $\mathrm{mm}^{2}$ y diámetro tangencial con Calophyllum eoinophyllum, en cuanto al parénquima con C. cuddalorense, C. eoinophyllum, C. dharmendrae, $C$. gogalacherraensis y $C$. intermedium, con respecto a los radios es más similar a C. eoinophyllum por la presencia de radios 1-2 seriados. Por lo tanto, se asigna el ejemplar LPP-CZS 0193 a la especie Calophyllum eoinophyllum Prakash, 1965, debido a que comparte los caracteres de vasos, parénquima $\mathrm{y}$ radios (Tabla 3 ).

Orden MYRTALES Reichenbach, 1828

Familia COMBRETACEAE Brown, 1810

Terminalioxylon Schönfeld, 1949

Especie tipo. Terminalioxylon naranjo Schönfeld, 1949.

Terminalioxylon erichsenii Mussa, 1958

(Figuras 9-10)

Afinidad botánica. Combretaceae. Terminalia L.

Material estudiado. LPP-CZS 0226 PRE 06 Adicional. 0141 PRJ 6.

Procedencia estratigráfica. Formación Solimões.

Procedencia geográfica. Rio Juruá, Río Envira, Acre, Brasil. Descripción. Los fragmentos analizados poseen anillos de crecimiento indistintos o ausentes. La porosidad es difusa. Los vasos tienen un trayecto rectilíneo y presentan un patrón de distribución diagonal/radial; de contorno oval/ elíptico. Los elementos de vasos son predominantemente solitarios $(80 \%)$ pero también se observan múltiples radiales de $2(20 \%)$, poseen un diámetro tangencial promedio de $70 \mu \mathrm{m}(50-100 \mu \mathrm{m})$, con densidad promedio de $15(10-20)$ por $\mathrm{mm}^{2}$ (Figuras 9A-B, 10A). Elementos de vasos cortos a medianos, con una longitud de $200 \mu \mathrm{m}(100-600 \mu \mathrm{m})$, con paredes terminales rectilíneas/oblicuas y placas de perforación de tipo simples. Las puntuaciones intervasculares son alternas, ornadas y con diámetro promedio de $6 \mu \mathrm{m}$ (5-8) (Figuras 9C-D, 10A-B). Las fibras son simples, no septadas, de sección poligonal, con paredes gruesas y lumen que mide $5 \mu \mathrm{m}(6-8 \mu \mathrm{m})$ de diámetro (Figuras 9B, 10C). El parénquima axial paratraqueal es vasicéntrico, a veces unilateral y aliforme a confluente, algunas veces formando bandas con más de 3 células de alto (Figuras 9A-B). También se observa parénquima disyunto (Figura 10D). Los radios son numerosos, se encuentran en un promedio de 10 (8-18) por mm lineal, exclusivamente uniseriados, heterogéneos, constituidos por células procumbentes y cuadradas o erectas, tipo III de Kribs. Presentan una altura de $265 \mu \mathrm{m}(50-500 \mu \mathrm{m})$ y $20 \mu \mathrm{m}(10-30 \mu \mathrm{m})$ de ancho. La altura en número de células es de 10 (6-20) (Figuras 9E-F, 10E). Las puntuaciones radiovasculares son similares 

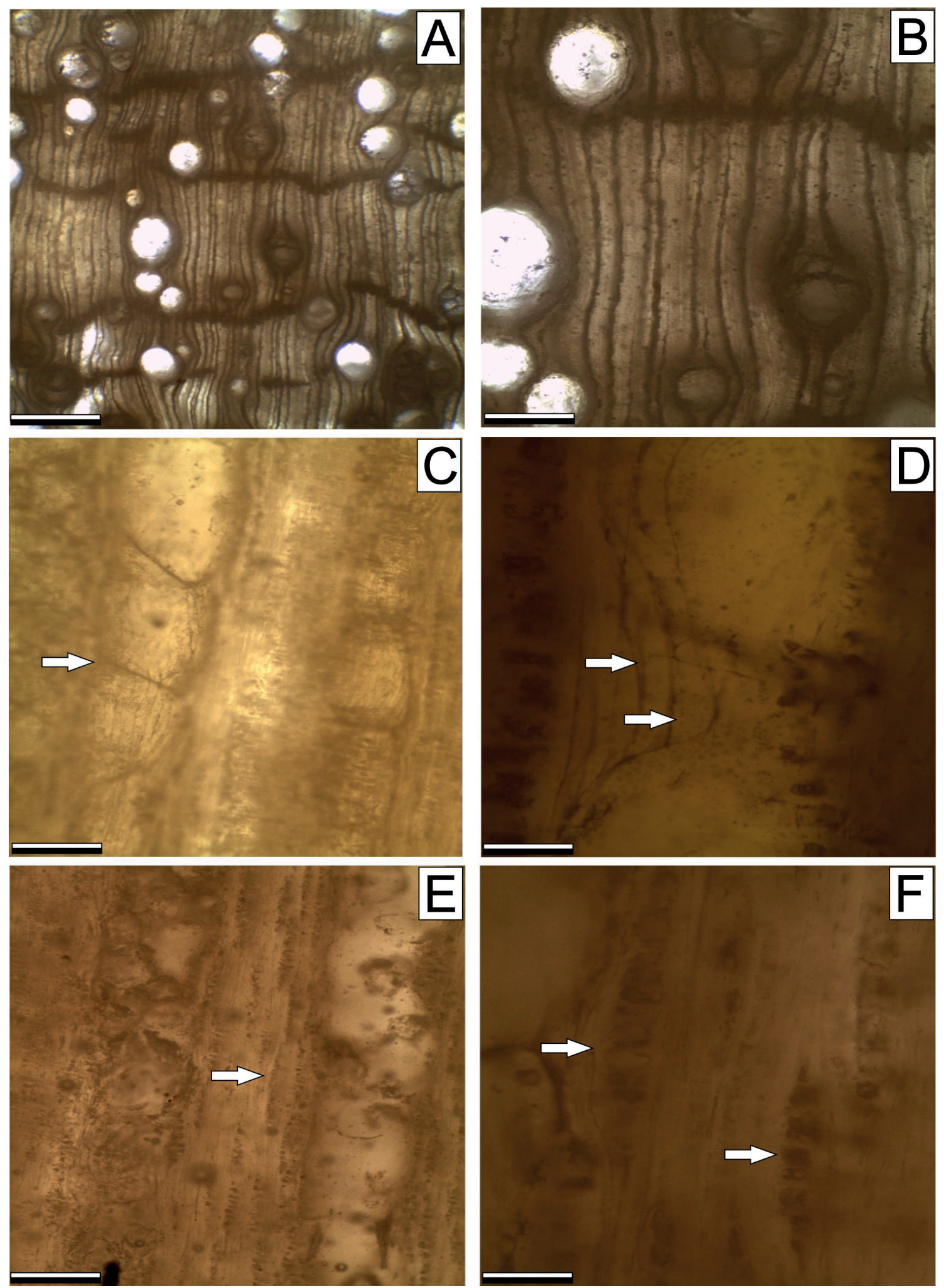

Figura 7. Calophylloxylon eoinophyllum (LPP-CZS 0194). MO. A, (CT), vasos exclusivamente solitarios y parénquima axial apotraqueal en bandas/líneas irregulares con dos a cuatro células de alto. B, (CT), detalle de vasos solitarios y parénquima axial apotraqueal en líneas. C (CLR), miembros de vasos cortos a medianos. D, (CLT), traqueidas vasculares/vasicéntricas. E-F, (CLT), radios heterogéneos, la mayoría uniseriados. Abreviaturas en Material y Métodos. Escalas: $A, E=200 \mu \mathrm{m} ; \mathrm{B}, \mathrm{D}, \mathrm{F}=100 \mu \mathrm{m} ; \mathrm{C}=50 \mu \mathrm{m}$.

Figure 7. Calophylloxylon eoinophyllum (LPP-CZS 0194). O.M. A, (TS), exclusively solitary vessels and axial apotracheal parenchyma in irregulary bands/lines with two to four cells high. B, (TS), detail of solitary vessels and apotracheal axial parenchyma in lines. C, (LRS), members of vessels short to medium. D, (LTS), vasculary/vasicentric tracheids. E-F, (LTS), rays heterogeneous mostly uniseriate. Abbreviations in Material and Methods. Scale bars: A, E = $200 \mu \mathrm{m} ; \mathrm{B}, \mathrm{D}, \mathrm{F}=100 \mu \mathrm{m} ; \mathrm{C}=50 \mu \mathrm{m}$. 

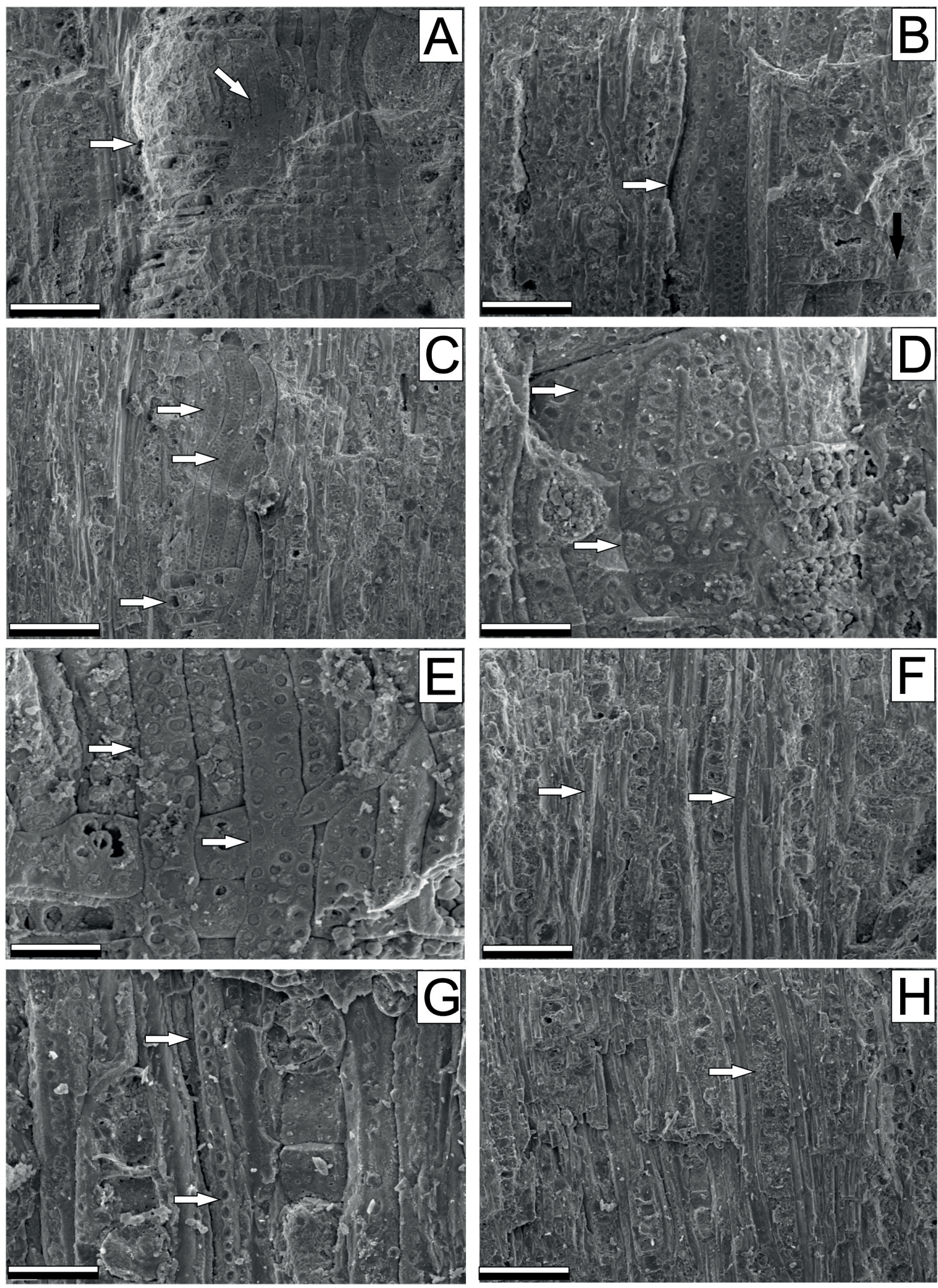

Figura 8. Calophylloxylon eoinophyllum (LPP-CZS 0194). MEB. A, vista general de un miembro de vaso. B-E, detalle de traqueidas vasculares/ vasicéntricas sobre los vasos y sus puntuaciones areoladas. $\mathbf{F}-\mathbf{G}$, fibrotraqueidas con puntuaciones areoladas. $\mathbf{H}$, radios heterogéneos mayoría uniseriados. Abreviaturas en Material y Métodos. Escalas: A-D, F-H $=200 \mu \mathrm{m} ; \mathrm{E}=100 \mu \mathrm{m}$.

Figure 8. Calophylloxylon eoinophyllum (LPP-CZS 0194). SEM. A, overview of a vessel member. B-E, detail of vasculary/vasicentric tracheids on the vessels and their borders. F-G, fibrotracheids with bordered pits. $\mathbf{H}$, rays heterogeneous mostly uniseriate. Abbreviations in Material and Methods. Scale bars: A-D, F-H = $200 \mu \mathrm{m} ; \mathrm{E}=100 \mu \mathrm{m}$. 


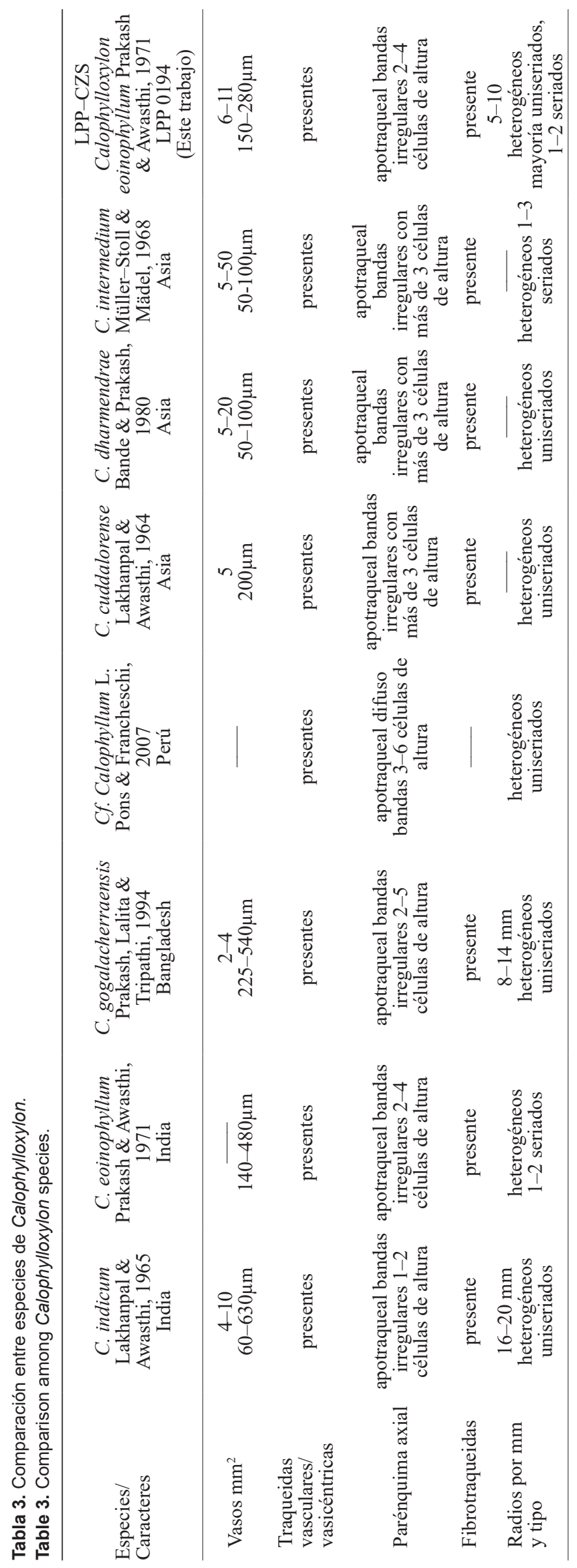

a las intervasculares. Presencia de cristales (Figura 10F). Observaciones. Según Metcalfe \& Chalk, (1950) la anatomía de la familia Combretaceae está caracterizada por la presencia de vasos solitarios y múltiples, placas de perforación simples, puntuaciones alternas, ornadas, parénquima típicamente aliforme a confluente, ocasionalmente vasicéntrico y en bandas, traqueidas vasicéntricas presentes en algunos géneros. Radios típicamente uniseriados, pocos géneros con biseriados. Este conjunto de caracteres permitieron incluir a los ejemplares analizados en la familia Combretaceae, presentando una estrecha relación con Terminalia por poseer: porosidad difusa, vasos solitarios y/o múltiples, vasos con diámetros cortos, placas de perforación simples, puntuaciones intervasculares alternas y ornadas, radios generalmente uniseriados, de homogéneos a heterogéneos, parénquima axial paratraqueal escaso, en algunos géneros aliforme, confluente o bandeado e infrecuentemente marginal (Metcalfe \& Chalk, 1950; Détienne \& Jacquet, 1983; Miller \& Détienne, 2001).

La familia Combretaceae posee cerca de 13 géneros y 500 especies, con distribución tropical (Figura 12C), que se producen en ambientes cálidos de todos los continentes, con los centros de diversidad en África y Asia. Las especies de esta familia son integrantes importantes de los manglares, selvas tropicales y las regiones semiáridas (Stace, 2004). En Brasil, ocurren seis géneros con aproximadamente 70 especies que crecen en casi todas las formaciones vegetacionales brasileñas (Maquete \& Valente, 2006).

De acuerdo con Exell \& Stace (1966), Combretaceae está dividida en dos subfamilias: Strephonematoideae, sin representantes en la flora brasileña, y Combretoideae, dividida en dos tribus: Laguncularieae y Combreteae las cuales poseen representantes en la flora neotropical. El género Terminalia pertenence a Combretoideae y se distribuye en todos los continentes. La complejidad taxonómica y filogenética de la subfamilia Combretoideae es reconocida por la mayoría de los autores, especialmente la amplia variación morfológica en flores, frutas y brotes vegetativos, según (Tan et al., 2002; Loiola et al., 2009).

Comparaciones con fósiles. En Sudamérica este taxón se describió por primera vez con dos especies, Terminalioxylon naranjo Schönfeld, 1947 y T. porosum Schönfeld, 1947 en Colombia (Schönfeld, 1947). Posteriormente, Mussa (1958) crea T. erichsenii para la Formación Barreiras de Brasil; Mirioni (1965) la especie T. portae para Colombia y recientemente T. lajaum Ramos et al., 2012 de la Formación El Palmar (Argentina).

Los especímenes descriptos en esta contribución fueron comparados con Terminalioxylon naranjo, T. porosum, $T$. erichsenii, T. edwardsii Müller \& Mädel, 1973, T. sivalicus Prasad, 1989, Anogeissoxylon rehmanense Ahmed et al., 2007, y T. lajaum (Tabla 4). Los ejemplares se diferencian de T. naranjo porque poseen radios exclusivamente uniseriados y mayor densidad por mm lineal, con T. porosum se diferenció porque posee vasos con mayor diámetro tangencial y por los radios 1-2 seriados; de T. edwardsii, T. sivalicus, y $T$. lajaum por la densidad de vasos por $\mathrm{mm}^{2}$ y por los radios 1-2 seriados, fibras septadas y cristales. Se distingue de 


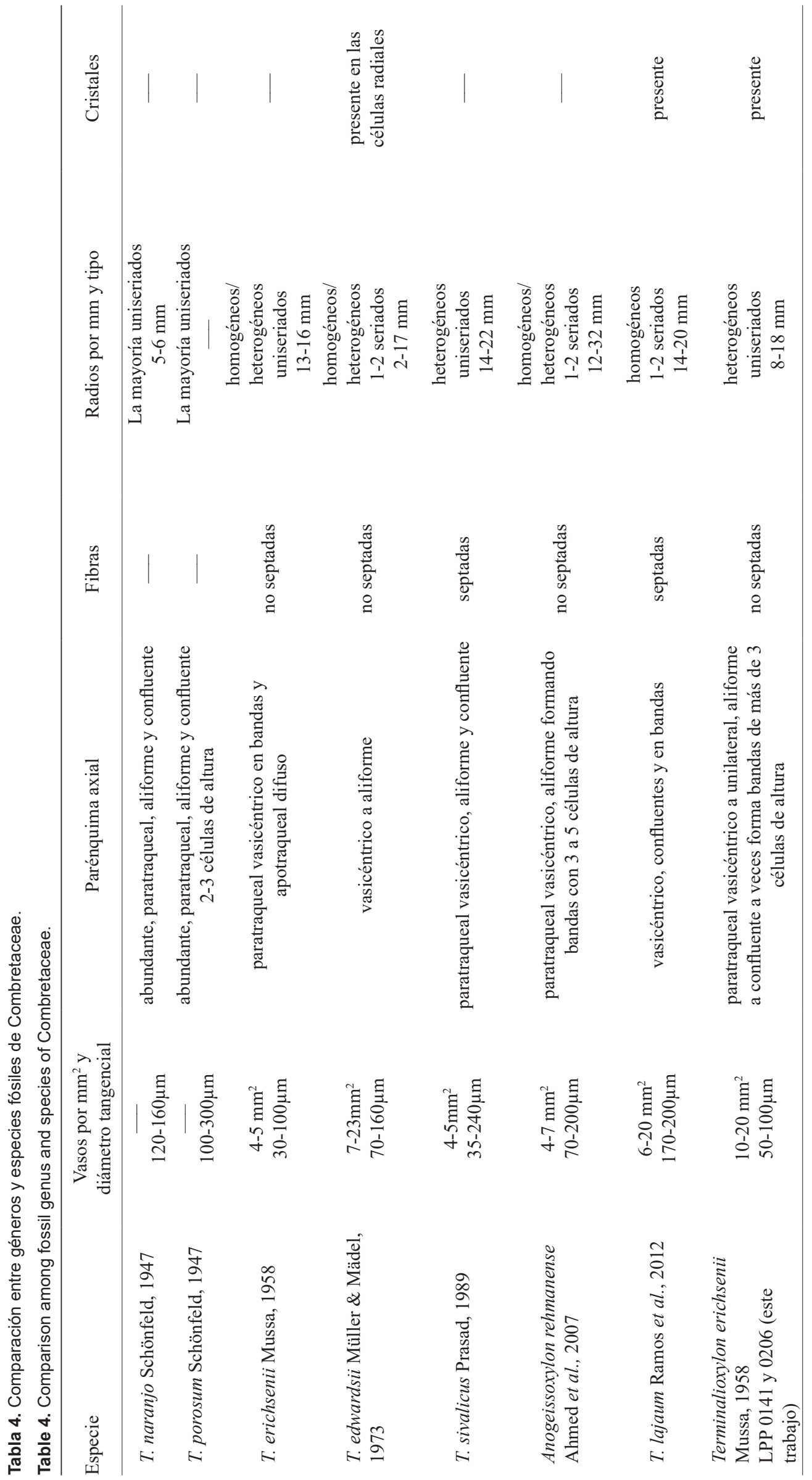



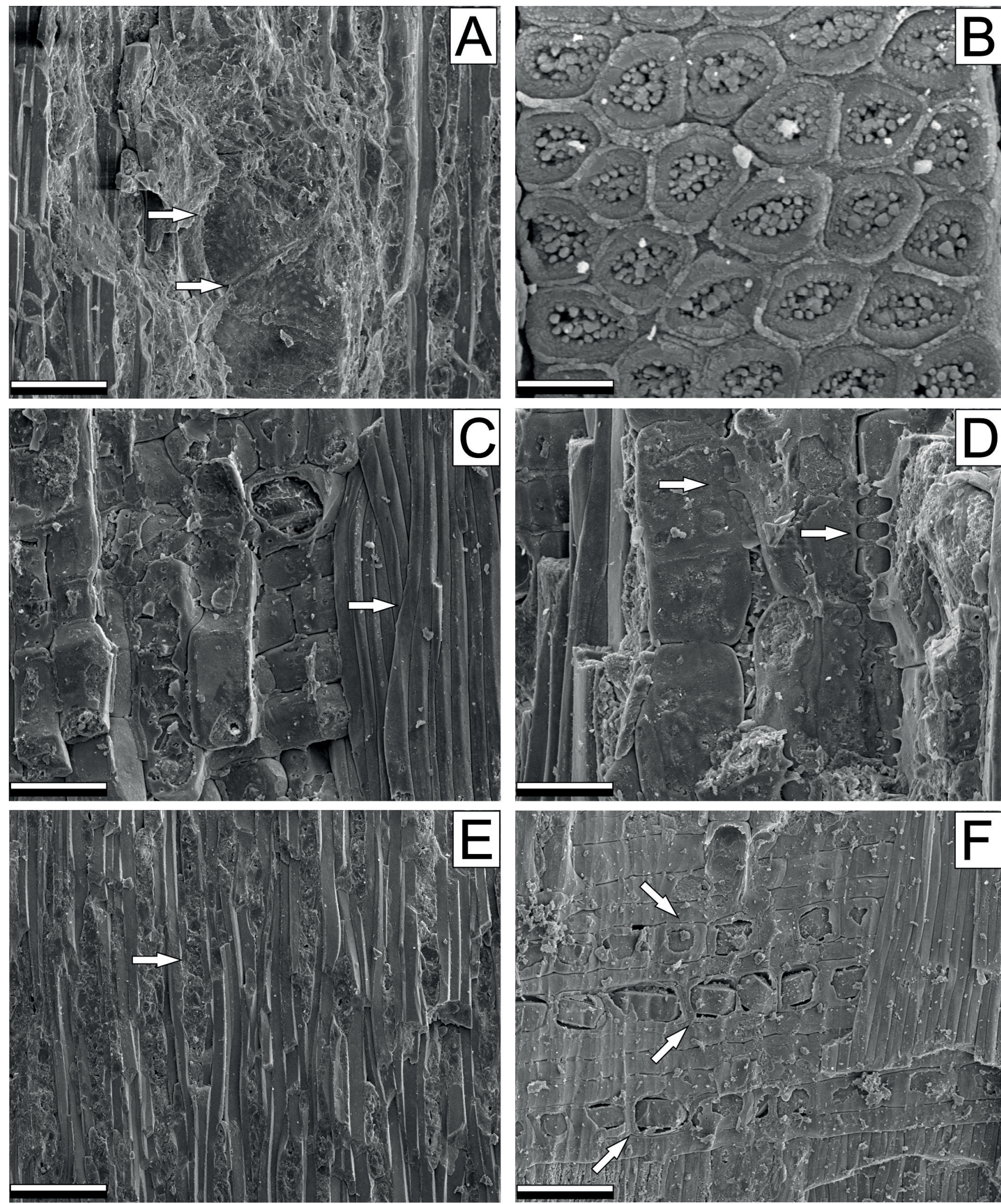

Figura 9. Terminalioxylon erichsenii (LPP-CZS 0141). MO. A-B, (CT), vasos solitarios y múltiples, parénquima axial paratraqueal escaso y apotraqueal poco a veces formando bandas de una a dos células de alto. B, detalle de una vaso solitario, parénquima y fibras. C, (CLR), puntuaciones intervasculares alternas. D, (CLR), placas de perforación simples. E-F, (CLT), radios heterogéneos mayoría uniseriados. Abreviaturas en Material y Métodos. Escalas: $A=200 \mu \mathrm{m} ; \mathrm{B}, \mathrm{E}=100 \mu \mathrm{m} ; \mathrm{C}-\mathrm{D}, \mathrm{F}=50 \mu \mathrm{m}$.

Figure 9. Terminalioxylon erichsenii (LPP-CZS 0141). O.M A-B, (TS), solitary and multiple vessels, axial paratracheal parenchyma sparse and apotracheal sometimes forming bands of one to two cells high. B, detail of a solitary vessels, parenchyma and fibers. C, (LRS), alternate intervascular pits. D, (LRS), simple perforation plates. E-F, (LTS), rays heterogeneous mostly uniseriate. Abbreviations in Material and Methods. Scale bars: $A=200 \mu \mathrm{m} ; \mathrm{B}, \mathrm{E}=100 \mu \mathrm{m} ; \mathrm{C}-\mathrm{D}, \mathrm{F}=50 \mu \mathrm{m}$. 

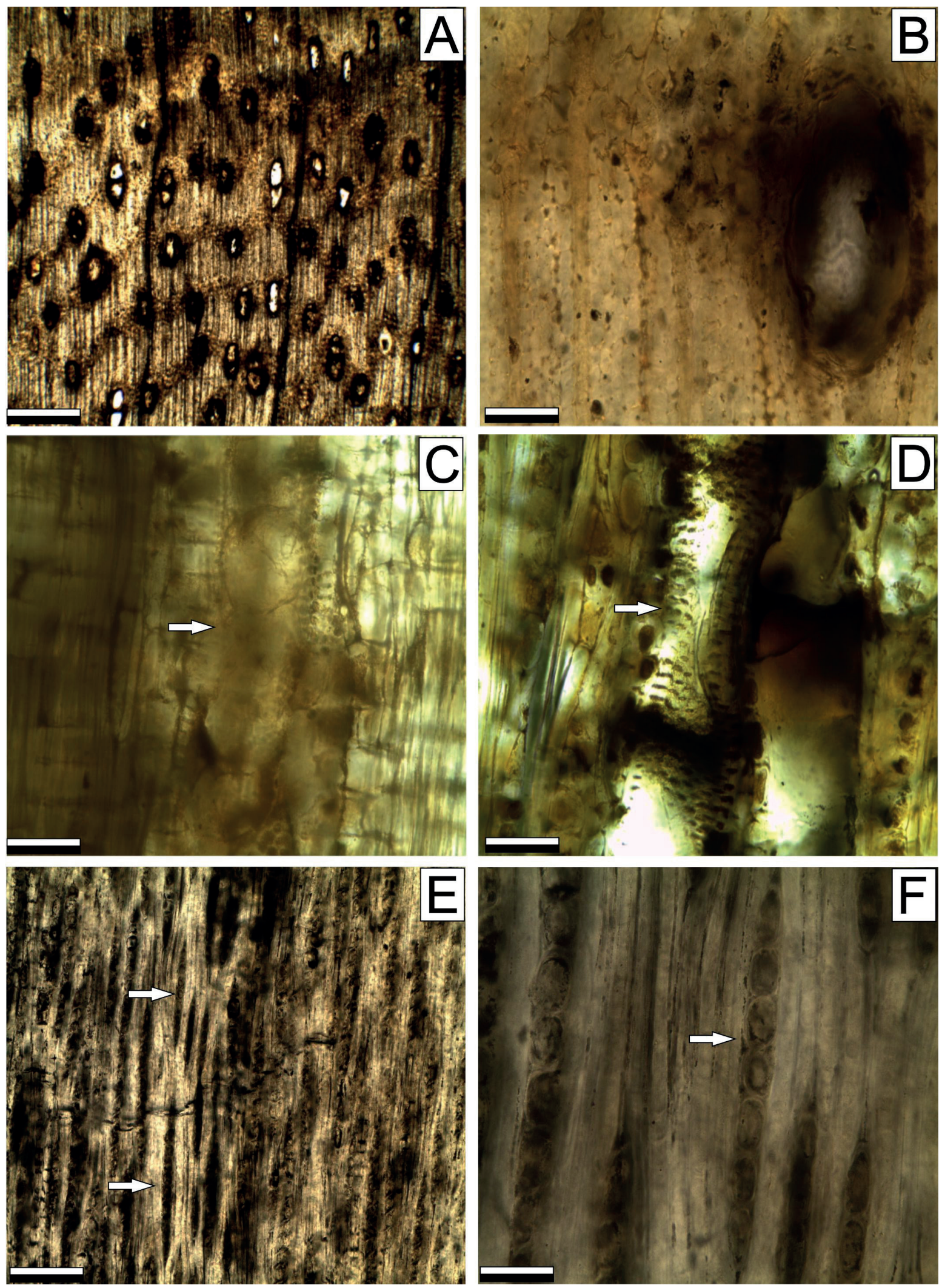

Figura 10. Terminalioxylon erichsenii (LPP-CZS 0141). MEB. A, vasos solitarios y placa de perforación simple (flecha). B, puntuaciones intervasculares ornadas. C, detalle de las fibras simples. D, parenquima disyunto. E, radios heterogéneos mayormente uniseriados. F, presencia de cristales en cámaras del parénquima radial. Abreviaturas en Material y Métodos. Escalas: $A-B, D=100 \mu \mathrm{m} ; C=10 \mu \mathrm{m}$.

Figure 10. Terminalioxylon erichsenii (LPP-CZS 0141). SEM. A, solitary vessels and simple perforation plate (arrow) B, vestured intervessel pits. C, detail of the simple fibers. D, disjunctive parenchyma. $\mathbf{E}$, rays heterogeneous mostly uniseriate. $\mathbf{F}$, presence of crystals in chambers in the radial parenchyma. Abbreviations in Material and Methods. Scale bars: A-B, D = $100 \mu \mathrm{m} ; \mathrm{C}=10 \mu \mathrm{m}$. 
Anogeissoxylon rehmanense por la densidad de vasos por $\mathrm{mm}^{2}$ y por los radios 1-2 seriados. La única diferencia que los ejemplares presentaron con $T$. erichsenii fue la densidad de vasos por $\mathrm{mm}^{2}$, por ello, se determina taxonómicamente como T. erichsenii (Tabla 4).

Orden ARECALES Bromhead, 1840
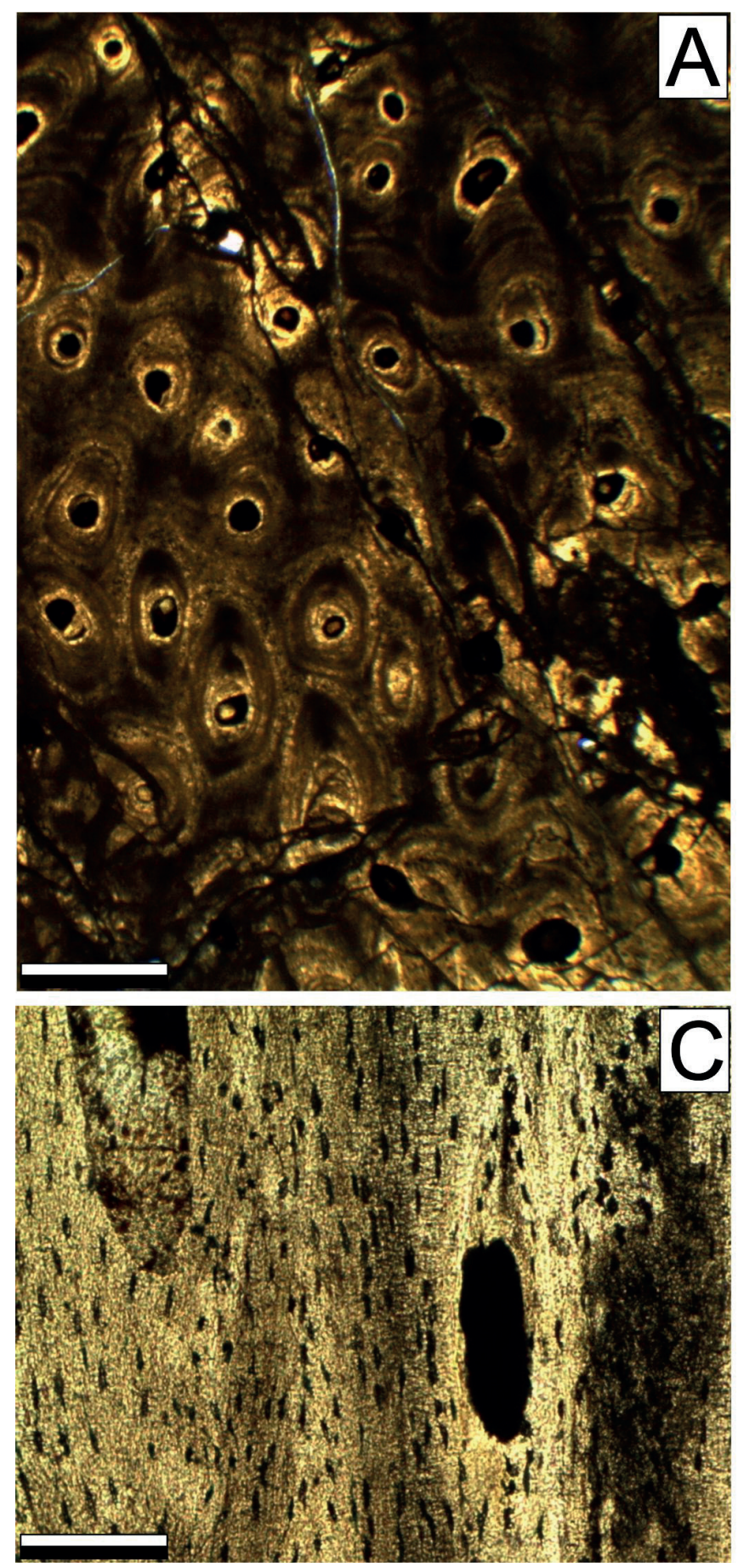

Familia ARECACEAE Berchtold \& J. Presl, 1820

Palmoxylon Schenk, 1882

Especie-tipo. Palmoxylon blanfordii Schenk, 1882.

Palmoxylon sp.

(Figura 11)
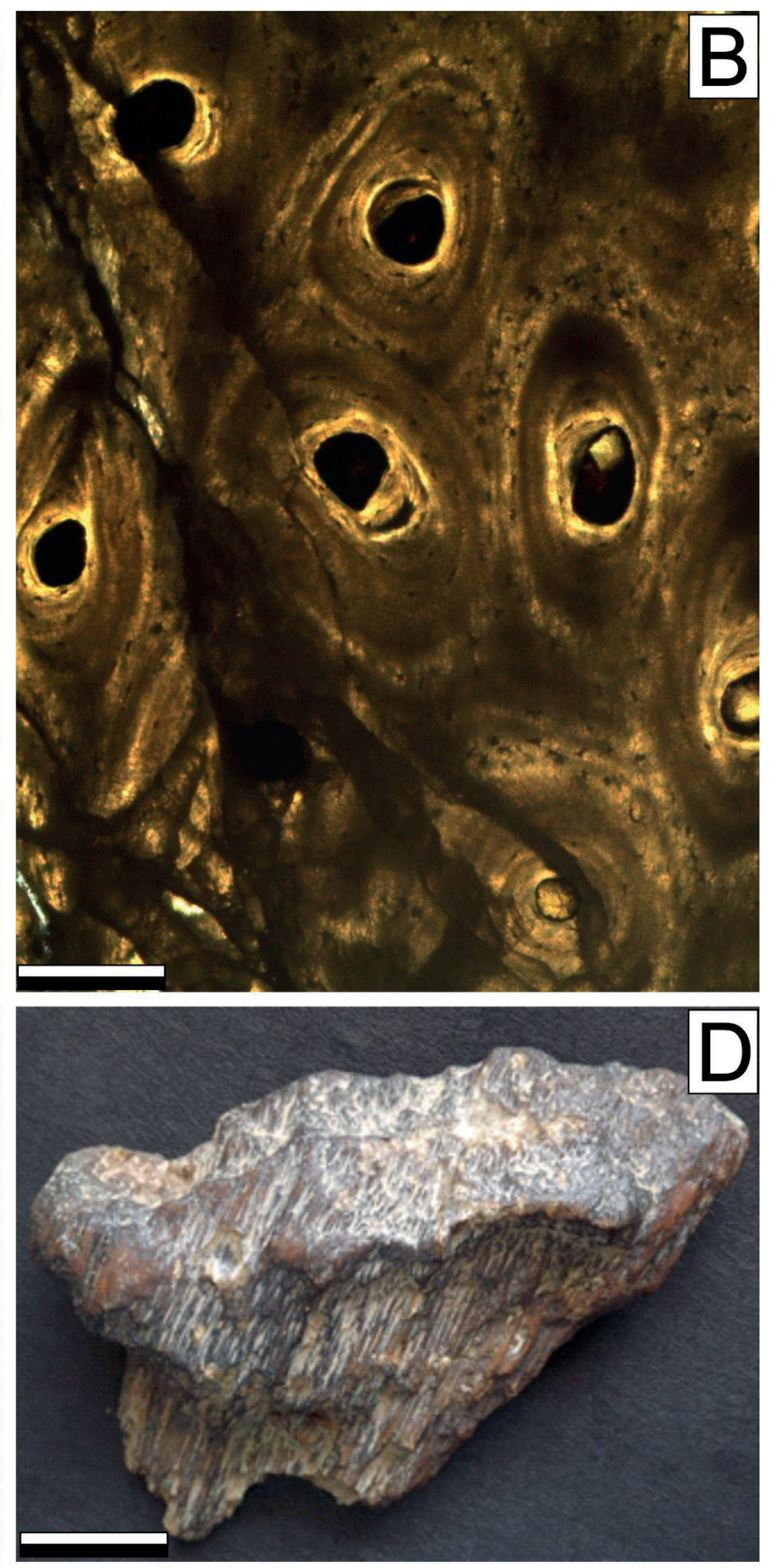

Figura 11. Palmoxylon (LPP-CZS 0127). A-B, (CT) haces fibrovasculares y metaxilema C, (CLR), haces fibrovasculares. D- vista general del ejemplar. Abreviaturas en Material y Métodos. Escalas: A, C, D = $100 \mu \mathrm{m} ; \mathrm{B}=50 \mu \mathrm{m}$.

Figure 11. Palmoxylon (LPP-CZS 0127). A-B, (TS), fibrovascular bundles and metaxylem. C, (LRS), fibrovasculary stems. D, overview of the specimen. Abbreviations in Material and Methods. Scale bars: A, C, D = $100 \mu \mathrm{m} ; \mathrm{B}=50 \mu \mathrm{m}$. 
Afinidad botánica. Arecales. Arecaceae. Berchtold y J. Presl. Material estudiado. LPP-CZS 0127 PRJ 6.

Procedencia estratigráfica. Formación Solimões.

Procedencia geográfica. Río Juruá, Acre, Brasil.

Descripción breve. Fragmento de palmera fósil de aproximadamente $15 \mathrm{~cm}$ de largo. El ejemplar no se encuentra en buen estado de preservación, lo que dificulta la observación y descripción de los caracteres anatómicos. Únicamente fue posible distinguir, en corte transversal, algunos haces fibrovasculares de aproximadamente $50 \mu \mathrm{m}(50-100 \mu \mathrm{m}) \mathrm{y}$ elementos de vasos del metaxilema.

Comparaciones. Debido a las pocas características anatómicas reconocibles y escasez de información por mal preservación del material solo se lo puede relacionar al género fósil Palmoxylon.

Observaciones. Las palmeras constituyen un grupo de plantas arbóreas, tropicales, monocotiledóneas, pertenecientes a la familia Arecaceae (Henderson et al., 1995; Cabral \& Castro, 2007 en Franco, 2014).

En la actualidad, la mayoría de estos grupos fueron reasignados o reagrupados en base a caracteres moleculares en cinco subfamilias: Calamoideae, Nypoideae, Coryphoideae,
Ceroxyloideae y Arecoideae (Asmussen et al., 2006; Martínez, 2010 en Franco, 2014).

Arecaceae es un grupo monofilético que incluye 183 géneros y 2364 especies aproximadamente (Govaerts \& Dransfield, 2005 en Navarro et al., 2009). Actualmente, la mayoría de las palmeras están distribuidas en los trópicos con pocas especies habitando los subtrópicos (Figura 12D) (Henderson et al., 1995). El registro fósil refleja una distribución latitudinal más amplia de las palmas a fines del Mesozoico y Cenozoico temprano debido a un clima más cálido global. Jassen \& Bremer (2004) y Bremer \& Jassen (2005) defienden la hipótesis de que las palmeras se habrían originado en Australia (incluso Nueva Guinea, Nueva Caledonia y Nueva Zelandia) y su centro de origen estaría estimado en $110 \mathrm{Ma}$.

Las palmeras en Brasil están representadas por especies arbustivas, y arbóreas. Dentro de las que forman las especies arbóreas, con estípite en madera se encuentran: Copernicia cerifera Mart, Syagrus ramanzofiana Cham, S. camosa Mart, Attalea hoehnei Burret, Acrocomia intumescens Drude, Euterpe oleracea Mart, E. eduls Mart, Mauritia flexuosa L.,
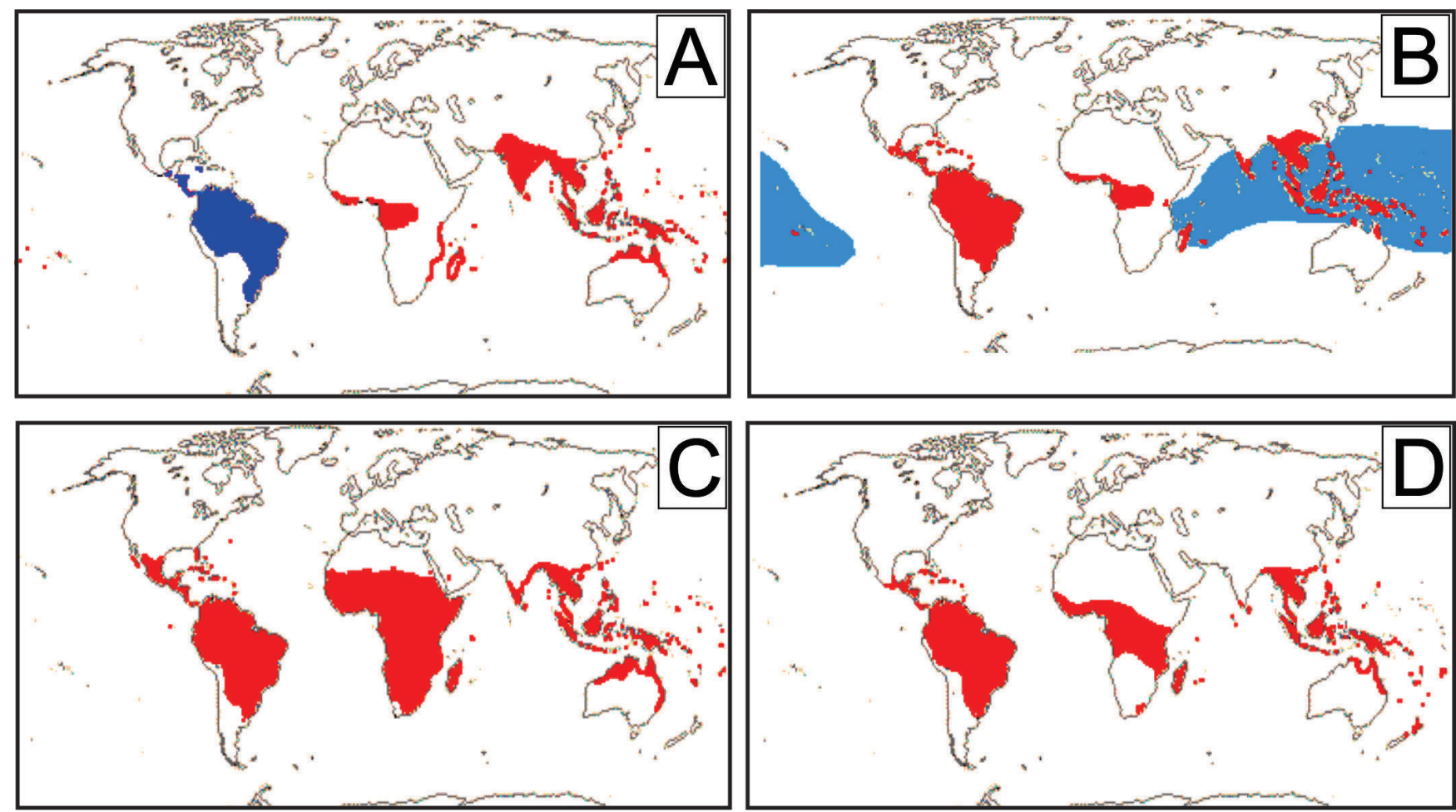

Figura 12. Mapas de distribución actual de las familias. A, Lecythidaceae. En azul las subfamilias (Lecythioideae y Napoleonaeoideae) que se encuentran en América y en rojo las demás subfamilias. B, familia Calophyllaceae con distribución neotropical (rojo) desde México, Panamá, Bolivia, Ecuador, Guayanas, Perú, Venezuela y Brasil. En (azul) la distribución de la especie Calophyllum inophyllum, C, familia Combretaceae con distribución tropical. D, familia Arecaceae con distribución tropical. Mapas tomados y adaptados de http://www.mobot.org/MOBOT/research/ APweb/.

Figure 12. Current distribution maps of families. A, Lecythidaceae. In blue the subfamilies (Lecythioideae and Napoleonaeoideae) found in America and in red the other subfamilies. B, Calophyllaceae family, in (red) neotropical distribution, from Mexico, Panama, Bolivia, Ecuador, Guayanas, Peru, Venezuela to Brazil. In (Blue) the distribution of the species Calophyllum inophyllum. C, Combretaceae family with tropical distribution. D, Arecaceae family with tropical distribution. Maps taken and adapted from http://www.mobot.org/MOBOT/research/APweb/. 
Maximiliana regia Mart, y Scheelea pharelata Burret (Paula \& Alves, 2007).

\section{CONCLUSIONES}

En este trabajo se describieron cinco nuevos registros de maderas fósiles para la Formación Solimões: Carinianoxylon brasiliense y Lecythioxylon enviraense $\mathrm{n}$. $\mathrm{sp}$. para la familia Lecythidaceae, Calophyloxylon eoionophyllum de la familia Calophyllaceae, Terminalioxylon erichensii perteneciente a Combretaceae y Palmoxylon sp. de la familia Arecaceae.

La paleoflora de la Formación Solimões analizada hasta el momento muestra una gran riqueza en cuanto a la diversidad de grupos taxonómicos. Los estudios comparativos realizados permitieron concluir que los taxones identificados comparten mayor similitud con respecto a los presentes en otras formaciones de la misma franja latitudinal, como por ejemplo, en India. Esto concuerda con el hecho de que éstas ya se encontraban a latitudes tropicales en el Mioceno, y se cree que las temperaturas eran análogas a las actuales.

\section{AGRADECIMIENTOS}

Las autoras agradecen el proyecto 01200.001631/201032 MCTI, Brasil, coordinado por K. Adami-Rodrigues. Las autoras también agradecen al P. Détienne por la bibliografía suministrada, al F.R. Negri y la Universidad Federal de Acre por los préstamos de la colección. Agradecemos también a la A.M. Ribeiro y B. Schneider. Se agradece a los revisores de este trabajo por su precioso tiempo y aporte.

\section{REFERENCIAS}

Ahmed, B.; Rajput, M.T.M. \& Noor-Ul-Ain, S. 2007. Anogeissoxylon rehmanense sp. nov. a new fossil species of the family Combretaceae from Rehman Dhoro, District Jamshoro, Sindh, Pakistan. Pakistan Journal of Botany, 39:2337-2344.

APG III. 2009. An update of the Angiosperm Phylogeny Group classification for the orders and families of flowering plants: APG III. Botanical Journal of the Linnean Society, 161:105-121. doi:10.1111/j.1095-8339.2009.00996.x

APG IV. 2016. An update of the Angiosperm Phylogeny Group classification for the orders and families of flowering plants: APG IV. Botanical Journal of the Linnean Society, 181:1-20. doi:10.1111/boj.12385

Asmussen, C.B.; Dransfield, J.; Deickmann, V.; Barfod, A.S.; Pintaud, J.C. \& Baker, W.J. 2006. A new subfamily classification of the palm family (Arecaceae): evidence from plastid DNA phylogeny. Botanical Journal of the Linnean Society, 151:15-38. doi:10.1111/j.1095-8339.2006.00521.x

Aristeguieta, L. 2003. Estudio dendrológico de la flora de Venezuela. Caracas, Academia de Ciencias Físicas, Matemáticas y Naturales, 572 p.

Awasthi, N. 1969. On the ocurrence of two new fossil woods belonging to the family Lecythidaceae in the Tertiary rocks of south India. The Palaeobotanist, 18:67-74.

Bande, M.B. \& Prakash, U. 1980. Fossil woods from the Tertiary of West Bengal, India. Geophytology, 10:146-157.

Barros, C.F. \& Callado, C.H. 1997. Madeiras da Mata Atlântica. Anatomia do lenho de espécies ocorrentes nos remanescentes florestais do Estado do Rio de Janeiro- Brasil. Rio de Janeiro, Instituto de Pesquisas Jardim Botânico, 86 p.
Bremer, K. \& Jassen, T. 2005. Gondwanan origin of major monocot groups inferred from dispersal-vicariance analysis. Aliso, 22:22-27. doi:10.5642/aliso.20062201.03

Cabral, E.L. \& Castro, M. 2007. Palmeras Argentinas. Guía para el reconocimiento. Buenos Aires, Editorial Literature of Latin America, p. 88 p.

Caputo, M.V. 1984. Stratigraphy, tectonics, paleoclimatology and paleogeography of northern basins of Brazil. University of California, Ph.D. thesis, 583 p.

Carlquist, S. 2001. Comparative wood anatomy, systematic, ecological, and evolutionary aspects of dicotyledon wood. Berlin, Springer-Verlag, 448 p. doi:10.1007/978-3-662-04578-7

Chattaway, M. 1932. Proposed standards for numerical values used in describing woods. Tropical Woods, 29:20-28.

Cione, A.L. et al. 2000. Miocene vertebrates from Entre Ríos province, eastern Argentina. In: F.G. Aceñolaza \& R. Herbst (eds.) El Neógeno de Argentina, Buenos Aires, Asociación Paleontológica Argentina, p. 191-237 (Serie Correlación Geológica 14)

Détienne, P. \& Jacquet, P. 1983. Atlas of the woods of the Amazon and of adjoining regions (Atlas des bois de l'Amazanie et des regions voisines). Nogent-surmarne, Centre Technique Forestier Tropical, $640 \mathrm{p}$.

Exell, A.W. \& Stace, C.A. 1966. Revision of the Combretaceae Boletim Sociedade Broteriana, 40:5-25.

Frailey, C.D.; Lavina, E.; Rancy, A.Y \& Souza-Filho, J. 1988. A Proposed Pleistocene/Holocene lake in the Amazon Basin and its significance to Amazonian geology and biogeography. Acta Amazonica, 18:119-143. doi:10.1590/1809-43921988183143

Franco, M.J. 2014. Estípites de Arecaceae en la Formación Ituzaingó (Plioceno-Pleistoceno), Entre Ríos, Argentina. Acta geológica Lilloana, 26:14-29.

Gregory, M.; Poole, I. \& Wheeler, E.A. 2009. Fossil dicot wood names: an annotated list with full bibliography. Leiden, The International Association of Wood Anatomists, 220 p. (Journal Supplement 6).

Gross, M.; Piller, W.E.; Ramos, M.I. \& Paz, J.D.S. 2011. Late Miocene sedimentary environments in southwestern Amazonia (Solimões Formation, Brazil). Journal of South American Earth Sciences, 32:169-181. doi:10.1016/j.jsames.2011.05.004

Henderson, A.; Galeano, G. \& Bernal, R. 1995. Field guide to the palms of the Americas. Princeton, Princeton University Press, $313 \mathrm{p}$.

Hoorn, C. 1993. Miocene incursions and the influence of Andean tectonics on the Miocene deposicional history of Northwestern Amazonia: results of a palynostratigraphic study. Palaeogeography, Palaeoclimatology, Palaeoecology, 105:267-309. doi:10.1016/0031-0182(93)90087-Y

IAWA Committee. 1989. List of microscopic features for hardwood identification. Leiden, The International Association of Wood Anatomists, p. 219-332 (Bulletin 10).

Inside Wood Database. 2004. International Association of Wood Anatomists list of microscopic InsideWood. Available at http:// insidewood.lib.ncsu.edu/search; accessed on 07/14/2017.

Jaramillo, J.A.; Parra, S.L.N \& Rangel-C. 2011. El Registro de los cambios de clima en la estratigrafia de la Amazonía Colombiana I. Neógeno - Inicios Del Cuaternario. Caldasia, 33:539-572.

Kloster, A. 2015. Xilotafofloras de la Formación Solimões (Neógeno), estado de Acre, oeste de Amazonia, Brasil. Universidad Nacional de Cordoba, Tesis Doctoral, $235 \mathrm{p}$.

Kloster, A.; Gnaedinger, S.; Adami-Rodrigues, K. \& Urban, C. 2013. Novo registro de Zollernioxylon tinocoi Mussa (Fabaceae) no Vale do Juruá, Mioceno da Formação Solimões, Bacia do Acre, 
Brasil. Gaea - Journal of Geoscience, 82:26-32. doi:10.4013/ gaea.2012.81.04

Kloster, A.; Gnaedinger S.; Adami-Rodrigues K. \& Urban C. 2015. New record of Fabaceae fossil woods from the Solimões Formation (Miocene), Acre Basin, Amazon, Brazil. Revista Brasileira de Paleontologia, 18:391-402. doi:10.4072/ rbp.2015.3.05

Kribs, D.A. 1937. Salient lines of structural specialization in the wood parenchyma of dicotyledons. Bulletin of the Torrey Botanical Club, 64:177-187. doi:10.2307/2481141

Kronberg, B.I.; Benchimol, R.E. \& Bird, M.I. 1991. Geochemistry of Acre Subbasin sediments: window on ice-age Amazonia. Interciencia, 16:138-141.

Lakhanpal, R.N \& Awasthi, N. 1964. Fossil woods of Calophyllum from Tertiary of South India. The Palaeobotanist, 13:328-336.

Latrubesse, E.M. 1992. El cuaternario fluvial de la cuenca del Purus en el estado de Acre, Brasil. Tesis de Doctorado, Universidad Nacional de San Luis, 214 p.

Latrubesse, E.M.; Bocquentin, J.; Santos, C.R. \& Ramonell, C.G. 1997. Paleoenvironmental model for the late Cenozoic Southwestern Amazonia: paleontology and geology. Acta Amazonica, 27:103-118. doi:10.1590/1809-43921997272118

Latrubesse, E.M.; Cozzuol, M.; Silva-Caminha, S.A.F.; Rigsby, C.A.; Absy, M.L. \& Jaramillo, C. 2010. The Late Miocene paleogeography of the Amazon Basin and the evolution of the Amazon River system. Earth-Science Reviews, 99:99-124. doi:10.1016/j.earscirev.2010.02.005

Latrubesse, E.M.; Silva, S.A.F.; Cozzuol, M. \& Absy, M.L. 2007. Late Miocene continental sedimentation in Southwestern Amazonia and its regional significance: biotic and geological evidence. Journal of South American Earth Sciences, 23:61-80. doi:10.1016/j.jsames.2006.09.021

Lemoigne, Y. 1978 Flores tertiaires de la haute vallee de l'Omo (Ethiopie). Palaeontographica Abteilung B, 165:89-157.

Lens, F.; Baas, P.; Jansen, S. \& Smets, E. 2007. A search for phylogenetically informative wood characters within Lecythidaceae. American Journal of Botany, 94:483-502. doi:10.3732/ajb.94.4.483

León, W.J. 2008. Estudio anatómico de la madera en 17 especies de la familia Lecythidaceae de Venezuela. Revista Forestal Venezolana, 52:213-225.

Loiola, M.I.B.; Rocha, E.A.; Baracho, G.S. \& Agra, M.F. 2009. Flora da Paraíba: Combretaceae. Acta Botanica Brasilica, 23:330-342. doi:10.1590/S0102-33062009000200005

Machado, L.G.; Scheel-Ybert, R.; Bolzon, R.T.; Carvalho, A.M. \& Carvalho, S.I. 2012. Lenhos fósseis do Neógeno da Bacia do Acre, Formação Solimões: contexto paleoambiental. Revista Brasileira de Geociências, 42:67-80.

Maquete, N.F.S. \& Valente, N.M. 2006. Flora da Reserva Ducke, Amazonas, Brasil: Combretaceae. Rodriguésia, 56:131-140.

Martínez, C.L.A. 2010. Estudios xilológicos en el Cretácico de la Cuenca Neuquina, Provincia de Neuquén, Argentina. Facultad de Ciencias Naturales y Museo, Universidad Nacional de La Plata, Tesis Doctoral, 239 p.

Metcalfe, C.R. \& Chalk, L. 1950. Anatomy of the Dicotyledons. Oxford, Clarendon Press, $731 \mathrm{p}$.

Milanez, F.R. 1935. Estudo de um dicotyledoneo fossil do Cretaceo. Rodriguésia, 1:84-89.

Miller, R.B. \& Détienne, P. 2001. Major timber trees of Guyana. Wood Anatomy. Wageningen, Tropenbos International, $218 \mathrm{p}$.

Mironi, H. 1965. Étude anatomique de quelques bois Tertiares de Colombie. Santander, Universidad Industrial de Santander, p. 27-59 (Boletim de Geologia 20).
Mori, S.A. \& Prance, G.T. 1990. Lecythidaceae. In: The Zygomorphic-flowered New World Lecythidaceae (Couroupita, Corythophora, Bertholletia, Couratari, Eschweilera, and Lecythis), New York, The New York Botanical Garden, 376 p. (Flora Neotropica Monographs 21).

Mori, S.A. \& Prance, G.T. 1999. Lecythidaceae. In: J. Steyermark; P. Berry; B. Holst \& K. Yatskievych (eds.) Flora in the Venezuelan Guayana, volume 5, Missouri Botanical Garden Press, p. 750-779.

Müller-Stoll, W.R. \& Mädel, E. 1986. Ein neues Guttiferenholz aus dem Tertiär von Java, Calophylloxylon intermedium sp. nov. Feddes Repert, 97:225-233.

Mussa, D. 1958. Dicotiledôneo fóssil da Formação Barreiras, estado de Sergipe. Rio de Janeiro, Departamento Nacional de Produção Mineral, Divisão de Geologia e Mineralogia, p. 1-23 (Boletim 181).

Mussa, D. 1959. Contribuição à Paleoanatomia Vegetal. In: Madeiras fósseis do território do Acre, Alto Juruá, Brasil, Rio de Janeiro, Departamento Nacional de Produção Mineral, Divisão de Geologia e Mineralogia, 78 p. (Boletim 195).

Navarro, C.G.; Jaramillo, C.A.; Herrera, F.A.; Callejas, R. \& Wing, S.L. 2009. Palms (Arecaceae) from a Paleocene rainforest of northern Colombia. American Journal Botany, 96:1300-1312. doi:10.3732/ajb.0800378

Negri, F.R.; Bocquentin-Villanueva, J.; Ferigolo, J. \& Antoine, P.O. 2010. A review of Tertiary mammal faunas and birds from western Amazonia. In: C. Hoorn \& F.P. Wesselingh (eds.) Amazonia: landscape and species evolution: a look into the past, Wiley-Blackwell, p. 245-258. doi:10.1002/9781444306408. $\operatorname{ch} 15$

Paula, J.E. \& Alves, J.L.H. 2007. 897 madeiras nativas do Brasil. Anatomia, dendrologia, dendrometria, produção, uso. Porto Alegre, Cinco continentes, $438 \mathrm{p}$.

Paula-Couto, C. 1983. Fossil mammals from the Cenozoic of Acre, Brazil VI - Edentata Cingulata. Iheringia, Série Geologia, 8:1-149.

Pons, D. \& Franceschi, D. 2007. Neogene woods from western Peruvian Amazon and paleoenviromental interpretation. Bulletin of Geoscience, 82:343-354. doi:10.3140/bull. geosci.2007.04.343

Prakash, U. 1965. Some fossil dicotyledonous woods from the Tertiary of eastern India. The Palaeobotanist, 14:223-235.

Prakash, U. \& Awasthi, N. 1971. Fossil woods from the Tertiary of eastern India II. The Palaeobotanist, 18:219-225.

Prakash, U.; Vaidyanathan, L. \& Tripathi, P.P. 1994. Plant remains from the Tipam Sandstones of northeast India with remarks on the palaeoecology of the region during the Miocene. Palaeontographica Abteilung B, 231:113-146.

Prasad, M. 1989. Some more fossil woods from the Lower Siwalik sediments of Kalagarh, Uttar Pradesh, India. Geophytology, 18:135-144.

Radambrasil. 1977. Geologia. In: Projeto Radambrasil - Programa de Integração Nacional, Rio de Janeiro, Ministério das Minas e Energias, Departamento Nacional da Produção Mineral, p. 17-123 (Levantamento de Recursos Naturais 14).

Radambrasil. 1978. Folha, S.A., 20 Manaus, Geologia, Geomorfologia, Pedologia, Vegetação, uso Potencial da Terra. In: Projeto Radambrasil - Programa de Integração Nacional, Rio de Janeiro, Ministério das Minas e Energias, Departamento Nacional da Produção Mineral (Levantamento de Recursos Naturais 18).

Ramos, R.S.; Brea, M. \& Kröhling, D.M. 2012. Leños Fósiles de la Formación El Palmar (Pleistoceno Tardío) en el Parque Nacional 
El Palmar, Entre Ríos, Argentina. Ameghiniana, 49:606-622. doi:10.5710/AMGH.17.5.2012.561

Ranzi, A. 2000. Paleoecologia da Amazônia: megafauna do Pleistoceno. Florianópolis, Editora da UFSC, 101 p.

Ribeiro, A.M.; Madden, R.H.; Negri, F.R.; Kerber, L.; Hsiou, S.A. \& Rodrigues, K.A. 2013. Mamiferos fósiles y biocronología em el Sureste de la Amazonia, Brasil. In: D. Brandoni \& J.I. Noriega (eds.) El Neógeno de la Mesopotamia Argentina, Buenos Aires, Asociación Paleontológica Argentina, p. 207-221 (Publicación Especial 14).

Schenk, A. 1882. Die von den Gebrüdern Schlagenwelt in Indien gesammelten fossilen Hölzer. Botanischer Jahrbücher fur Systematik, Panzengeschichte und Panzengeographie, 3:353358.

Schönfeld, G. 1947. Hölzer aus den Tertiär von Kolumbien. Abhandlungen der Senckenbergischen Naturforschenden Gesellschaft, 474:1-53.

Selmeier, A. 2003. First record of a Lecythidaceae wood (Carinianoxylon brasiliense gen. et sp. nov.) from the Tertiary of the New World (Brazil, Rio Paranaiba). Zitteliana A, 43:171-178.

Stace, C.A. 2004. Combretaceae. In: N. Smith; S.A. Mori; A. Henderson; D.W. Stevenson \& S.V. Heald (eds.) Flowering plants of the neotropics, The New York Botanical Garden, $\mathrm{p}$. $110-111$.
Stevens, P.F. 2001. Angiosperm phylogeny website. Version 13, July 2017. Available at http://www.mobot.org/MOBOT/research/ APweb/; accessed on 07/14/2017.

Tan, F.; Shi, S.; Zhong, Y.; Gong, X. \& Wang, Y. 2002. Phylogenetic relationships of Combretoideae (Combretaceae) inferred from plastid, nuclear gene and spacer sequences. Journal of Plant Research, 115:475-481. doi:10.1007/s10265-002-0059-1

Zeeuw, C. 1990. Wood and timber. In: A.R.A. Gorts-van Rijn (ed.) Lecythidaceae, Oberreifenberg, Koeltz Scientific Books, p. 89-113 (Flora of the Guianas 53).

Zeeuw, C. 1992. Secondary xylem of Neotropical Lecythidaceae. In: S. Mori \& G. Prance (eds.) Lecythidaceae Part II, New York, New York Botanical Graden, p. 4-59 (Flora Neotropica Monograph 21).

Westaway, R. 2006. Late Cenozoic sedimentary sequences in Acre state, southwestern Amazonia: Fluvial or tidal? Deductions from the IGCP 449 fieldtrip. Journal of South American Earth Sciences, 21:120-134. doi:10.1016/j.jsames.2005.08.004

Received in August, 2017; accepted in December, 2017. 